\title{
Surgery for primary supratentorial brain tumors in the United States, 2000-2009: effect of provider and hospital caseload on complication rates
}

\author{
*Victoria T. Trinh, MD, Jason M. Davies, MD, PhD, and Mitchel S. Berger, MD \\ Department of Neurological Surgery, University of California, San Francisco, California
}

OBJECT The object of this study was to examine how procedural volume and patient demographics impact complication rates and value of care in those who underwent biopsy or craniotomy for supratentorial primary brain tumors.

METHODS The authors conducted a retrospective cohort study using data from the Nationwide Inpatient Sample (NIS) on 62,514 admissions for biopsy or resection of supratentorial primary brain tumors for the period from 2000 to 2009 . The main outcome measures were in-hospital mortality, routine discharge proportion, length of hospital stay, and perioperative complications. Associations between these outcomes and hospital or surgeon case volumes were examined in logistic regression models stratified across patient characteristics to control for presentation of disease and comorbid risk factors. The authors further computed value of care, defined as the ratio of functional outcome to hospital charges.

RESULTS High-case-volume surgeons and hospitals had superior outcomes. After adjusting for patient characteristics, high-volume surgeon correlated with reduced complication rates ( $O R=.91, p=0.04)$ and lower in-hospital mortality (OR $0.43, p<0.0001$ ). High-volume hospitals were associated with reduced in-hospital mortality (OR $0.76, p=0.003)$, higher routine discharge proportion (OR 1.29, $p<0.0001)$, and lower complication rates $(O R 0.93, p=0.04)$. Patients treated by high-volume surgeons were less likely to experience postoperative hematoma, hydrocephalus, or wound complications. Patients treated at high-volume hospitals were less likely to experience mechanical ventilation, pulmonary complications, or infectious complications. Worse outcomes tended to occur in African American and Hispanic patients and in those without private insurance, and these demographic groups tended to underutilize high-volume providers.

CONCLUSIONS A high-volume status for hospitals and surgeons correlates with superior value of care, as well as reduced in-hospital mortality and complications. These findings suggest that regionalization of care may enhance patient outcomes and improve value of care for patients with primary supratentorial brain tumors.

http://thejns.org/doi/abs/10.3171/2014.9.JNS131648

KEY WORDS supratentorial brain tumors; oncology; caseload; complications; Nationwide Inpatient Sample

$\mathrm{P}$ ROVIDING access to high-quality, affordable health care continues to be a matter of physician and public concern. As legislation seeks to optimize cost and quality, it is important to examine the factors that contribute to differences in health outcomes. ${ }^{19}$ Hospital and surgeon case volume have been shown to impact outcomes across a variety of subspecialties, including neurosurgery, $2,3,7,8,25$ cardiothoracic surgery, ${ }^{15,20}$ gastrointestinal surgery, ${ }^{4,13,24}$ and breast surgery. ${ }^{14}$

Previous studies have demonstrated volume relationships with mortality and discharge disposition after biopsy or resection of primary brain tumors. ${ }^{2,21}$ From 1988 to
2000, there was a trend toward centralization of care with disproportionate growth in case volume at high-volume centers and a reduction at low-volume hospitals. ${ }^{2}$ Racial and socioeconomic disparities were also identified, and it has been shown that ethnic minorities are more likely to receive care at low-volume hospitals. ${ }^{6}$

The aims of this study were three-fold: 1) to establish whether trends toward centralization in the 1990s continued into the new millennium, 2) to examine the relationship of volume to in-hospital mortality, routine discharge, and complications, and 3) to compare the value of care across institutions.

ABBREVIATIONS ICD-9-CM = International Classification of Diseases, Ninth Revision, Clinical Modification; LOS = length of stay; NIS = Nationwide Inpatient Sample. SUBMITTED July 31, 2013. ACCEPTED September 18, 2014.

INCLUDE WHEN CITING Published online November 14, 2014; DOI: 10.3171/2014.9.JNS131648.

DISCLOSURE The authors report no conflict of interest concerning the materials or methods used in this study or the findings specified in this paper.

* Drs. Trinh and Davies contributed equally to this work. 


\section{Methods \\ Database}

We obtained data from the Nationwide Inpatient Sample (NIS) discharge database for the years 2000-2009. The NIS is the largest inpatient care database, containing $100 \%$ of discharges from a stratified random sample of nonfederal hospitals in 37 states, representing approximately $20 \%$ of all inpatient admissions to nonfederal hospitals in the United States. It is sponsored by the Agency for Healthcare Research and Quality under the Healthcare Cost and Utilization Project. It is a de-identified data set that does not permit tracking of patients across multiple hospitalizations. For this reason, all outcome variables were assessed over the course of the index admission.

\section{Inclusion and Exclusion Criteria}

The NIS was queried for all hospital inpatients aged 18 years or older with a primary diagnosis code corresponding to supratentorial primary brain tumor (191.0-5 or 191.8-9 [malignant brain tumor, excluding cerebellum or brainstem], 225.0 [benign brain tumor], 237.5 [brain tumor of uncertain behavior]) and primary procedure of 01.13 (closed brain biopsy), 01.14 (open brain biopsy), 01.53 (lobectomy), or 01.59 (other brain resection). Although it is not possible to identify histopathological tumor type based on International Classification of Diseases, Ninth Revision, Clinical Modification (ICD-9-CM) codes, these codes were previously used to identify primary brain tumor. ${ }^{2}$ Per ICD-9 coding guidelines, "benign" refers to neoplasms that are noninvasive and slow growing. In adults, neurilemmomas and pituitary tumors compose the majority of benign tumors (coded 225.x). Examples of coding for malignant neoplasms (coded 191.x) include astrocytoma, ependymoma, glioblastoma, neuroblastoma, and oligodendroglioma. We excluded patients with the code most commonly used to identify brain metastasis (198.3, secondary malignant neoplasm of brain or spinal cord).

\section{Study End Points}

Primary end points of the study were in-hospital mortality, routine discharge percentage, length of stay (LOS), and perioperative complications. Routine discharge percentage is defined as the proportion of patients who were discharged directly from hospital to home without the need for rehabilitation services. We further computed the value of care, defined as the ratio of functional outcome (routine discharge percentage) to cost of care to the payer (hospital charges; Appendix Value of Care).

\section{Patient Demographics}

Patient age on hospital admission, sex, race, primary payer for the hospital stay, weekend admission, reason for admission, and admission type were extracted from the NIS. Certain predictors of outcome, such as extent of resection, tumor enhancement, and use of intraoperative electrophysiological monitoring, were not available in the NIS data set and thus could not be assessed.

To evaluate for the effect of general medical comorbidity, a set of medical comorbidity markers described by
Elixhauser at al. were used with software provided by the Agency for Healthcare Research and Quality. ${ }^{12}$ A comorbidities index was created by summing each of the categories to calculate a composite comorbidity score.

We identified potential complications following brain tumor surgery, coded as follows: neurological complication including from infarction or hemorrhage (ICD-9-CM codes 997.00-997.09), hematoma complicating a procedure (ICD-9-CM codes 998.1-998.13), hydrocephalus (ICD-9-CM codes 331-331.4), performance of ventriculostomy (ICD-9-CM code 02.2), mechanical ventilation (ICD-9-CM codes 96.70, 96.72), pulmonary complications (ICD-9-CM codes 518.5, 518.81, 518.84, 997.3), pneumonia (ICD-9-CM codes 48.1, 48.2, 48.6), deep venous thrombosis complications (ICD-9-CM codes 415.11, 453.40, 453.8, 453.9), cardiac complications (ICD-9-CM codes 997.1, 41.0), wound infection complications (ICD9-CM codes 998.32, 998.51, 998.6, 998.81, 998.83), infectious complications (ICD-9-CM codes 595.0, 595.9, 599.0), implant complications (ICD-9-CM codes 996.2, 996.63, 996.75, 996.79), laceration (ICD-9-CM code 998.2), or decubitus ulcer (ICD-9-CM codes 707.01-09).

\section{Hospital and Provider Demographics}

Hospital location (rural or urban), teaching status, and bed capacity (small, medium, large) were coded in the NIS data. Hospital and surgeon volumes for brain tumor surgery were derived by counting cases for each identified hospital or surgeon in the database for a given year. Based on yearly case volume, hospitals and surgeons were divided into quartiles, as well as another group defined as the highest decile volume. The lowest quartile $(\leq 25$ th percentile) hospitals had fewer than 5 cases/year. The highest decile ( $\geq 90$ th percentile) hospitals had more than 34 or more cases/year. The lowest quartile ( $\leq 25$ th percentile) surgeons had 1 or fewer cases/year. The highest decile $(\geq$ 90th percentile) surgeons had 11 or more cases/year (Appendix Table 1). "Low" and "high" volume refer to the lowest and highest quartiles, respectively, and "very high" volume refers to the top decile providers. For ease in comparisons, we used the same standard as Barker et al. and primarily compared Quartiles 1 and 4 for the assessment of volume effects. ${ }^{2}$

\section{Statistical Analysis}

Correlations between demographic variables and primary outcome measures were assessed using SPSS (version 20, IBM Corp.) and JMP (version 10, SAS Institute). Statistical significance was calculated using the chi-square or Fisher exact test, Wilcoxon rank-sum test, nonparametric tests including the Mann-Whitney and median tests, and binary and ordinal logistic regression analysis, as appropriate. Normality between demographic variables and hospital and surgeon quartiles was assessed graphically and with SPSS software by using normal QQ plots and the absolute skewness statistic of $(|x|<1)$. Hospital charges and value of care data were analyzed as logarithmic transformations to correct for positive skew. The independentsamples Kruskal-Wallis test was used as a nonparametric alternative to the 1-way ANOVA for the hospital LOS. 
TABLE 1. Clinical characteristics of patients who underwent biopsy or craniotomy for primary brain tumors, 2000-2009

\begin{tabular}{|c|c|}
\hline Characteristic & Value \\
\hline Total no. of patients & 62,514 \\
\hline Median patient age on admission in yrs (IQR) & $59(47-71)$ \\
\hline Female sex (\%) & $27,300(44)$ \\
\hline \multicolumn{2}{|l|}{ Race $(\%)^{*}$} \\
\hline White & $37,959(82)$ \\
\hline AA & $2648(6)$ \\
\hline Hispanic & $3354(7)$ \\
\hline Asian/Pacific Islander & $883(2)$ \\
\hline Native American & $188(0.4)$ \\
\hline Other race & $1525(3)$ \\
\hline \multicolumn{2}{|l|}{ Admission type $(\%)^{*}$} \\
\hline Emergency & $16,872(31)$ \\
\hline Urgent & $10,513(19)$ \\
\hline Routine & $27,633(50)$ \\
\hline \multicolumn{2}{|l|}{ Admission source $(\%)^{*}$} \\
\hline Emergency room & $13,888(27)$ \\
\hline Acute care facility & $4905(9)$ \\
\hline Long-term care facility & $944(2)$ \\
\hline Routine & $32,487(62)$ \\
\hline \multicolumn{2}{|l|}{$\begin{array}{l}\text { Median household income for postal code of } \\
\text { residence (\%) }\end{array}$} \\
\hline 25th percentile & $584(3)$ \\
\hline 50th percentile & $3547(20)$ \\
\hline 75th percentile & $4621(26)$ \\
\hline 100th percentile & $9163(51)$ \\
\hline \multicolumn{2}{|l|}{ Insurance $(\%)^{*}$} \\
\hline Medicare & $23,939(38)$ \\
\hline Medicaid & $4790(8)$ \\
\hline Private & $29,456(47)$ \\
\hline Self-pay & $2183(3)$ \\
\hline No charge & $217(0.3)$ \\
\hline Other & $1800(3)$ \\
\hline Median comorbidity score (range) & $1(0-9)$ \\
\hline Median LOS in days (IQR) & $5(2-9)$ \\
\hline \multicolumn{2}{|l|}{ Hospital charge in US\$ } \\
\hline 25th percentile & $14,140.00$ \\
\hline 50th percentile & $23,819.00$ \\
\hline 75th percentile & $41,050.51$ \\
\hline 100th percentile & $883,967.00$ \\
\hline \multicolumn{2}{|l|}{ Discharge proportion (\%) ${ }^{*}$} \\
\hline Routine & $39,745(63.6)$ \\
\hline Short-term & $1019(1.6)$ \\
\hline Transfer to other facility & $13,248(21.2)$ \\
\hline Home health & $6682(10.7)$ \\
\hline Dead & $1642(2.6)$ \\
\hline \multicolumn{2}{|l|}{ Year of treatment (\%) } \\
\hline 2000-2004 & $30,261(48.4)$ \\
\hline $2005-2009$ & $32,253(51.6)$ \\
\hline
\end{tabular}

$\mathrm{AA}=$ African American; $\mathrm{IQR}=$ interquartile range.

* Factor not reported for all admissions.
Stepwise forward logistic regression was also used. We included all of the patient demographic factors available in the NIS data set, as shown in our tables. The exception was income, which was not included in the main analysis because of missing income data points in the top hospital and surgeon quartiles (fewer than 5 reported) for mortality. In our analysis, the final regression models included all statistically significant variables in the univariate analysis $(p<0.05)$ and variables that improved the model fit (increased the pseudo $\mathrm{R}^{2}$ statistic). Further details of this analysis can be found in the Appendix Evaluation of Model. We also computed a value parameter, defined as outcome/cost. In this computation, routine discharge percentage was the surrogate for outcome, and mean hospital charges (in $\$ 100,000$ ) were a surrogate for cost. Income was included in the value of care model but not in our main analysis, because more data were available for routine discharge and hospital charge for this parameter. Further details of this analysis can be found in the Appendix Value of Care.

\section{Results}

There were 62,514 admissions for biopsy or resection of supratentorial primary brain tumors from 2000 to 2009. Of these admissions, 58,195 (93.1\%) were for malignant tumor, 2168 (3.5\%) for benign tumor, and 2154 (3.4\%) for tumor of uncertain behavior. Open procedures were performed in $43.8 \%$ of the admissions, including for open biopsy (23.6\%), resection (12.5\%), and lobectomy (7.7\%). Closed needle biopsy was performed in $56.2 \%$ of admissions. Clinical characteristics of the patients are shown in Table 1. Most patients were white, between 47 and 71 years of age, and male. Half of the admissions were classified as routine, $31 \%$ as emergencies, and $19 \%$ as urgent. Admission from home (62\%) was most common, followed by emergency room (27\%) and acute care facility (9\%).

There were fewer admissions to low-volume centers and a rise in admissions to the highest quartile hospitals over the entire period spanning 2000-2004 and 20052009. From the first to the second half of the study period, the number of low-volume hospitals decreased from 7588 to 7177 , and the number of high-volume hospitals increased slightly from 1521 to 1592 . The mean annual hospital caseload increased from 15 to 19 cases per hospital from the first to the second half of the study, although the mean surgeon caseload volume remained stable at 5 cases per surgeon. The percentage of patients treated at centers where no other biopsy or resection was reported decreased from $4.7 \%$ to $3.7 \%$. Similarly, we observed a decrease from $14.2 \%$ to $12.6 \%$ for low-volume surgeons where no other biopsy or resection was reported that year.

The in-hospital mortality rate for the cohort as a whole was $2.6 \%$. The mortality rate was $1.9 \%$ for needle biopsy, $3.1 \%$ for open brain biopsy, $2.7 \%$ for lobectomy, and $5.0 \%$ for other resection. Patients were discharged directly home in $74.5 \%$ of cases (including $10.7 \%$ with home health), with $21.2 \%$ transferred to long-term facilities and $1.6 \%$ going to short-term facilities. The routine discharge proportion was $68.7 \%$ for closed brain biopsy, $58.4 \%$ for open brain biopsy, $63.2 \%$ for lobectomy, and $51.3 \%$ for other resection 
(Appendix Table 2). The median LOS was 5 days for the cohort. The LOS was shortest for closed brain biopsy at a median of 4 days, followed by craniotomy at a median of 7 days.

\section{Patient Demographics and Outcome}

Age, sex, race, primary payer, admission type, weekend admission, and type of procedure were tested as predictors of mortality and discharge (Tables 2-3). Age was an important predictor of outcome at the time of hospital discharge when stratified as follows: 18-30 years, 31-44, $45-64,65-84$, and 85 or older ( $<<0.001)$. African Americans had higher mortality and a worse routine discharge percentage in the univariate analysis; in the multivariate model, African American race remained an independent predictor of in-hospital mortality (OR 1.76, 95\% CI 1.35$2.28, \mathrm{p}<0.001)$ but did not reach significance for routine discharge (OR 0.89, 95\% CI 0.79-1.00, $\mathrm{p}=0.053$ ). Compared with emergent or urgent admissions, elective admissions patients had reduced mortality (OR $0.29,95 \%$ CI $0.24-0.36, \mathrm{p}<0.001)$ and an increased routine discharge percentage (OR 2.34, 95\% CI 2.20-2.49, p < 0.001). Increases in the medical comorbidity score were associated with higher mortality and worse routine discharge percentage $(\mathrm{p}<0.001)$.

\section{Hospital and Surgeon Characteristics and Outcome}

Patients were treated at 1026 hospitals, with 4296 surgeons identified in the database. The majority of patients (77.8\%) were treated at teaching hospitals with a large bed capacity, $16.7 \%$ were treated at hospitals with a medium bed capacity, and $5.5 \%$ were treated at hospitals with a small bed capacity. Analyzed on a per patient basis, the mean annual number of brain tumor biopsies or craniotomies was 17 per hospital (range 1-142 procedures) or 5 per surgeon (range 1-29). Appendix Table 1 shows the breakdown of cases into volume quartiles, as well as the highest-volume decile, for both surgeons and hospitals. For 2618 patients (4.2\%), no other biopsy or resection was reported that year at their particular hospital; and for 8350 patients (13.4\%), no other biopsy or resection was reported that year by their surgeon.

Patient characteristics were tested for their association with provider volume (Tables 4 and 5 and Appendix Table $3)$. There was a tendency for those treated by high-volume providers to be younger $(\mathrm{p}<0.001)$, male $(\mathrm{p}<0.001)$, white $(\mathrm{p}<0.001)$, and with private insurance $(\mathrm{p}<0.001)$. Race was significantly correlated with both hospital and surgeon caseload (both $\mathrm{p}<0.001$ ). African Americans were significantly less likely than whites to receive brain tumor treatment at high-volume hospitals and from high-volume

TABLE 2. Prognostic value of patient characteristics for in-hospital mortality after biopsy or craniotomy for primary brain tumor

\begin{tabular}{|c|c|c|c|c|}
\hline \multirow[b]{2}{*}{ Factor } & \multicolumn{2}{|c|}{ Univariate Analysis } & \multicolumn{2}{|c|}{ Multivariate Analysis } \\
\hline & OR $(95 \% \mathrm{Cl})$ & p Value* & OR $(95 \% \mathrm{Cl})$ & $p$ Value* \\
\hline \multicolumn{5}{|l|}{ Age at time of admission in yrs } \\
\hline $18-30$ & 1.00 & & 1.00 & \\
\hline $31-44$ & $1.62(1.25-2.10)$ & $<0.001$ & $5.54(2.91-10.57)$ & $<0.001$ \\
\hline $45-64$ & $1.48(1.16-1.88)$ & 0.02 & $3.28(1.74-6.17)$ & $<0.001$ \\
\hline $65-84$ & $1.59(1.25-2.03)$ & $<0.001$ & $2.98(1.57-5.65)$ & 0.001 \\
\hline $85-95$ & $2.89(2.10-3.99)$ & $<0.001$ & $4.72(2.26-9.89)$ & $<0.001$ \\
\hline Female sex & $0.95(0.86-1.05)$ & 0.33 & $0.86(0.73-1.01)$ & 0.06 \\
\hline AA vs other race & $1.91(1.58-2.31)$ & $<0.001$ & $1.76(1.35-2.28)$ & $<0.001$ \\
\hline Elective admission & $0.30(0.26-0.34)$ & $<0.001$ & $0.29(0.24-0.36)$ & $<0.001$ \\
\hline Primary payer (private insurance vs other) & $0.61(0.51-0.73)$ & $<0.001$ & $1.11(0.91-1.35)$ & 0.310 \\
\hline \multicolumn{5}{|l|}{ Comorbidity score } \\
\hline 0 & 1.00 & & 1.00 & \\
\hline 1 & $2.86(1.50-2.32)$ & $<0.001$ & $1.62(1.22-2.15)$ & 0.001 \\
\hline $2-3$ & $2.37(1.93-2.91)$ & $<0.001$ & $1.92(1.47-2.52)$ & $<0.001$ \\
\hline $4-5$ & $6.11(4.86-7.68)$ & $<0.001$ & $4.29(3.17-5.81)$ & $<0.001$ \\
\hline $6-7$ & $6.37(4.19-9.70)$ & $<0.001$ & $4.58(2.78-7.53)$ & $<0.001$ \\
\hline $8-9$ & $25.66(13.60-48.43)$ & $<0.001$ & $22.81(11.58-44.93)$ & $<0.001$ \\
\hline \multicolumn{5}{|l|}{ Procedure type } \\
\hline Needle biopsy & 1.0 & & 1.0 & \\
\hline Open biopsy & $1.55(1.37-1.75)$ & $<0.001$ & $1.18(0.96-1.44)$ & 0.12 \\
\hline Craniotomy & $2.11(1.88-2.37)$ & $<0.001$ & $2.00(1.65-2.43)$ & $<0.001$ \\
\hline Weekend admission & $1.65(1.45-1.87)$ & $<0.001$ & $0.95(0.77-1.18)$ & 0.65 \\
\hline Hospital case vol, Quartile 4 vs 1 & $0.36(0.33-0.38)$ & $<0.0001$ & $0.76(0.63-0.90)$ & 0.003 \\
\hline Surgeon case vol, Quartile 4 vs 1 & $0.51(0.47-0.57)$ & $<0.001$ & $0.43(0.32-0.55)$ & $<0.0001$ \\
\hline
\end{tabular}

* Boldface $p$ values indicate significance. 
TABLE 3. Prognostic value of patient characteristics for routine discharge after biopsy or craniotomy for primary brain tumor

\begin{tabular}{|c|c|c|c|c|}
\hline \multirow[b]{2}{*}{ Factor } & \multicolumn{2}{|c|}{ Univariate Analysis } & \multicolumn{2}{|c|}{ Multivariate Analysis } \\
\hline & OR $(95 \% \mathrm{Cl})$ & p Value* & $\mathrm{OR}(95 \% \mathrm{Cl})$ & p Value* \\
\hline \multicolumn{5}{|l|}{ Age at admission in yrs } \\
\hline $18-30$ & 1.0 & & 1.0 & \\
\hline $31-44$ & $0.78(0.71-0.86)$ & $<0.001$ & $0.73(0.62-0.86)$ & $<0.001$ \\
\hline $45-64$ & $0.44(0.41-0.48)$ & $<0.001$ & $0.48(0.42-0.56)$ & $<0.001$ \\
\hline $65-84$ & $0.19(0.17-0.20)$ & $<0.001$ & $0.25(0.22-0.30)$ & $<0.001$ \\
\hline $85-95$ & $0.10(0.09-0.12)$ & $<0.001$ & $0.15(0.12-0.19)$ & $<0.001$ \\
\hline Female sex & $0.77(0.75-0.80)$ & $<0.001$ & $0.84(0.79-0.89)$ & $<0.001$ \\
\hline AA vs other race & $0.76(0.70-0.82)$ & $<0.001$ & $0.89(0.79-1.00)$ & 0.053 \\
\hline Elective admission & $2.82(2.71-2.92)$ & $<0.001$ & $2.34(2.20-2.49)$ & $<0.001$ \\
\hline Primary payer (private insurance vs other) & $2.47(2.38-2.55)$ & $<0.001$ & $1.20(1.12-1.29)$ & $<0.001$ \\
\hline \multicolumn{5}{|l|}{ Comorbidity score } \\
\hline 0 & 1.0 & & 1.0 & \\
\hline 1 & $0.41(0.38-0.44)$ & $<0.001$ & $0.60(0.55-0.66)$ & $<0.001$ \\
\hline $2-3$ & $0.20(0.19-0.22)$ & $<0.001$ & $0.36(0.33-0.39)$ & $<0.001$ \\
\hline $4-5$ & $0.09(0.08-0.10)$ & $<0.001$ & $0.21(0.19-0.24)$ & $<0.001$ \\
\hline $6-7$ & $0.04(0.03-0.06)$ & $<0.001$ & $0.11(0.08-0.15)$ & $<0.001$ \\
\hline $8-9$ & $0.02(0.01-0.05)$ & $<0.001$ & $0.03(0.01-0.09)$ & $<0.001$ \\
\hline \multicolumn{5}{|l|}{ Procedure type } \\
\hline Needle biopsy & 1.0 & & 1.0 & \\
\hline Open biopsy & $0.66(0.63-0.68)$ & $<0.001$ & $0.61(0.57-0.66)$ & $<0.001$ \\
\hline Craniotomy & $0.60(0.57-0.62)$ & $<0.001$ & $0.44(0.41-0.48)$ & $<0.001$ \\
\hline Weekend admission & $0.60(0.57-0.63)$ & $<0.001$ & $0.92(0.84-1.01)$ & 0.064 \\
\hline Hospital case vol, Quartile 4 vs 1 & $2.15(1.89-2.49)$ & $<0.0001$ & $1.29(1.21-1.37)$ & $<0.0001$ \\
\hline Surgeon case vol, Quartile 4 vs 1 & $1.28(1.19-1.38)$ & $<0.0001$ & $1.03(0.95-1.11)$ & 0.493 \\
\hline
\end{tabular}

* Boldface $p$ values indicate significance.

surgeons. In addition, private insurance patients were significantly more likely to obtain high-volume surgical care. Older patients and those admitted nonelectively were also more likely to obtain low-volume surgical care $(\mathrm{p}<0.001)$. Comorbidity trends were split, with low-volume hospitals treating more complex patients, but high-volume surgeons tending to treat patients with more comorbidities than their low-volume colleagues $(\mathrm{p}<0.001)$.

Outcomes at hospital discharge were more favorable for patients treated at high-volume centers and by highvolume surgeons (Figs. 1-2 and Appendix Tables 4 and 5 ). Hospital and surgeon case volumes were significantly correlated with in-hospital mortality $(\mathrm{p}<0.001)$, routine discharge $(\mathrm{p}<0.001)$, and LOS ( $\mathrm{p}<0.001)$. Routine discharge home occurred in $68.6 \%$ of patients treated at high-volume hospitals (Quartile 4) compared with 56.7\% of patients treated at low-volume hospitals (Quartile 1; OR $1.29,95 \%$ CI 1.21-1.37). In-hospital mortality was also lower in patients treated at high-volume hospitals (OR $0.76,95 \%$ CI $0.63-0.90)$. Patients treated by high-volume surgeons (Quartile 4) were less likely to die in the hospital (OR $0.43,95 \%$ CI $0.32-0.55$ ) than the patients treated by low-volume surgeons (Quartile 1). High-volume surgeons also had improved routine discharge proportion on uni- variate analysis (OR 1.28, 95\% CI 1.19-1.38), but this did not reach significance on multivariate analysis.

\section{Complications and Provider Caseload}

We studied several complications of surgery and perioperative care, including postoperative complication due to infarction or hemorrhage (2.6\%); hematoma (1.5\%); hydrocephalus (5.5\%); performance of a ventriculostomy $(5.3 \%)$; meningitis $(0 \%)$; postoperative thrombotic disorder including deep venous thrombosis, pulmonary embolism, and placement of an inferior vena cava filter (2.4\%); cardiac complications (0.5\%); renal complications (1.3\%); pulmonary complications (4.6\%); gastrointestinal complications $(0.6 \%)$; infectious complications $(5.2 \%)$; implant complications $(0.6 \%)$; accidental laceration $(0.2 \%)$; pneumonia (1.5\%); wound infection (0.8\%); and decubitus ulcer $(0.8 \%)$. Complications were more likely in craniotomies than in closed needle biopsies.

One or more complications were coded in $19.8 \%$ of cases $(12,349 / 62,514)$. The presence of one or more of these complications correlated significantly with increased mortality (OR 5.89, 95\% CI 4.96-6.99) and a worse routine discharge percentage (OR $0.30,95 \%$ CI $0.28-0.33$ ) in the multivariate analysis. A complication was more likely in 
TABLE 4. Relationship between patient characteristics and provider volume, comparing low (Quartile 1) and high (Quartile 4) quartiles

\begin{tabular}{|c|c|c|c|c|c|c|}
\hline \multirow[b]{2}{*}{ Factor } & \multicolumn{2}{|c|}{ Hospital Vol } & \multirow[b]{2}{*}{ p Value* } & \multicolumn{2}{|c|}{ Surgeon Vol } & \multirow[b]{2}{*}{ p Value* } \\
\hline & Quartile 1 & Quartile 4 & & Quartile 1 & Quartile 4 & \\
\hline Age in yrs & 60.2 & 56.3 & $<0.001$ & 58.5 & 56.9 & 0.011 \\
\hline Female & $44.1 \%$ & $44.4 \%$ & 0.597 & $45.2 \%$ & $44.4 \%$ & 0.336 \\
\hline Race & & & $<0.001$ & & & $<0.001$ \\
\hline White & $60.1 \%$ & $63.5 \%$ & & $64.3 \%$ & $72.8 \%$ & \\
\hline $\mathrm{AA}$ & $7.4 \%$ & $4.0 \%$ & & $7.2 \%$ & $6.8 \%$ & \\
\hline Hispanic & $5.3 \%$ & $4.5 \%$ & & $5.9 \%$ & $5.7 \%$ & \\
\hline In-hospital mortality & $2.3 \%$ & $0.7 \%$ & $<0.001$ & $3.8 \%$ & $1.3 \%$ & $<0.001$ \\
\hline Routine discharge proportion & $56.7 \%$ & $68.6 \%$ & $<0.001$ & $59.9 \%$ & $67.4 \%$ & $<0.001$ \\
\hline Total charges & $\$ 59,981$ & $\$ 54,273$ & 0.004 & $\$ 59,656$ & $\$ 56,270$ & 0.273 \\
\hline Private insurance & $39.4 \%$ & $50.9 \%$ & $<0.001$ & $44.4 \%$ & $48.7 \%$ & $<0.001$ \\
\hline Elective admission & $38.9 \%$ & $41.3 \%$ & $<0.001$ & $44.2 \%$ & $54.4 \%$ & $<0.001$ \\
\hline Comorbidity score & & & $<0.001$ & & & $<0.001$ \\
\hline 0 & $53.7 \%$ & $57.5 \%$ & & $56.7 \%$ & $49.5 \%$ & \\
\hline 1 & $17.1 \%$ & $18.2 \%$ & & $15.7 \%$ & $21.2 \%$ & \\
\hline $2-3$ & $22.3 \%$ & $20.6 \%$ & & $21.5 \%$ & $24.0 \%$ & \\
\hline $4-5$ & $6.0 \%$ & $3.3 \%$ & & $5.2 \%$ & $4.9 \%$ & \\
\hline $6-7$ & $0.8 \%$ & $0.4 \%$ & & $0.8 \%$ & $0.4 \%$ & \\
\hline $8-9$ & $0.2 \%$ & $0.0 \%$ & & $0.2 \%$ & $0.1 \%$ & \\
\hline
\end{tabular}

* Boldface $p$ values indicate significance.

patients with a comorbidity score of 1 or more (OR rising from 1.6 to 14.11 for an increasing comorbidity score from 1 to $9, \mathrm{p}<0.001)$ and for African Americans (OR 1.54, $95 \%$ 1.01-1.31, $\mathrm{p}=0.03$; Table 5). A complication was less likely in patients with private insurance (OR $0.85,95 \%$ CI $0.78-0.92, \mathrm{p}<0.001)$ and patients admitted electively (OR $0.44,95 \%$ CI $0.40-0.47, \mathrm{p}<0.001)$.

Several complications occurred less frequently at highvolume hospitals (Fig. 3) including mechanical ventilation (OR 0.51, p < 0.001), hydrocephalus (OR 0.87, p < $0.001)$, placement of ventriculostomy $(0.67, \mathrm{p}<0.001)$, and wound complications (OR 0.69, $\mathrm{p}=0.013$; Table 6). None of the complications occurred more frequently at the highvolume centers. Patients treated by high-volume surgeons were less likely to experience postoperative hematoma (OR 0.66, $\mathrm{p}=0.0001$ ), wound complications (OR 0.71, p $=0.029)$, or hydrocephalus (OR $0.85, \mathrm{p}=0.028)$. Patients treated both at high-volume hospitals and by high-volume surgeons were less likely to experience pulmonary ( $\mathrm{p}<$ $0.001)$ and infectious complications $(\mathrm{p}<0.001)$, as well as deep venous thrombosis and/or pulmonary embolism $(\mathrm{p}<0.05)$.

The unadjusted odds ratio for the occurrence of one or more complications is 0.87 (95\% CI 0.81-0.92) for patients treated at a high-volume hospital and 0.79 (95\% CI $0.73-$ 0.86 ) for patients treated by a high-volume surgeon. When adjusted for age, sex, race, medical comorbidity, insurance, procedure type, weekend admission, and admission type, both high-volume surgeon (OR 0.91, 95\% CI 0.84-0.99, $\mathrm{p}=0.040)$ and high-volume hospital (OR $0.93,95 \% \mathrm{CI}$ $0.87-0.99, p=0.040$ ) remained associated with fewer perioperative complications.

\section{Hospital Charges and Value of Care}

Indexed to year 2009 US\$, the mean total hospital charges increased significantly during the study period, from $\$ 33,900$ (2000) to $\$ 57,496$ (2009) for biopsies and from $\$ 62,439$ (2000) to $\$ 108,704$ (2009) for craniotomies. When adjusted for inflation, hospital charges increased by approximately $70 \%$ during this time period, with an average $7.7 \%$ and $8.2 \%$ increase per year for biopsy and craniotomy, respectively. The mean total charge at lowvolume hospitals (Quartile 1) was \$59,981 compared with $\$ 54,273$ at high-volume hospitals (Quartile 4). The mean total charge for low-volume surgeons (Quartile 1) was $\$ 59,656$ compared with $\$ 56,270$ for high-volume surgeons (Quartile 4). For both hospital and surgeon volumes, veryhigh-volume providers (top decile) had lower charges at $\$ 53,448$ and $\$ 44,442$, respectively. This trend toward reduced mean hospital charges for high-case-volume hospitals and surgeons was highly significant $(\mathrm{p}<0.001$; Fig. 4).

Computing the value of care as the ratio of outcomes to cost, higher-volume hospitals and surgeons provided superior value of care (Fig. 5). Value of care was compared across volume quartiles using 1-way ANOVA and was found to be significantly different. Games-Howell post hoc analysis revealed improved outcomes with an increased value of care ( $\mathrm{p}<0.001)$ at each interval (Appendix Tables 6 and 7). In the adjusted value of care analysis, "low-risk" patients (those with elective admissions, high income, private insurance, white race, low comorbidity score) consistently obtained the greatest benefit at the highest quartile. For African American and Hispanic patients and those without private insurance, higher-volume care was similarly associated with improved outcomes, although there 
TABLE 5. Effect of patient characteristics and provider volume on complications

\begin{tabular}{|c|c|c|c|c|}
\hline \multirow[b]{2}{*}{ Factor } & \multicolumn{2}{|c|}{ Univariate Analysis } & \multicolumn{2}{|c|}{ Multivariate Analysis } \\
\hline & OR $(95 \% \mathrm{Cl})$ & p Value* & OR $(95 \% \mathrm{Cl})$ & p Value* \\
\hline \multicolumn{5}{|l|}{ Age in yrs } \\
\hline $18-30$ & 1.0 & & 1.0 & \\
\hline $31-44$ & $0.70(0.65-0.77)$ & $<0.001$ & $0.58(0.50-0.67)$ & $<0.001$ \\
\hline $45-64$ & $0.71(0.66-0.77)$ & $<0.001$ & $0.46(0.41-0.53)$ & $<0.001$ \\
\hline $65-84$ & $0.75(0.70-0.81)$ & $<0.001$ & $0.39(0.34-0.45)$ & $<0.001$ \\
\hline $85-95$ & $0.85(0.75-0.98)$ & 0.023 & $0.51(0.41-0.64)$ & $<0.001$ \\
\hline Female sex & $1.15(1.10-1.19)$ & $<0.001$ & $1.13(1.06-1.21)$ & $<0.001$ \\
\hline AA vs other race & $1.78(1.63-1.94)$ & $<0.001$ & $1.54(1.01-1.31)$ & 0.030 \\
\hline Elective admission† & $0.38(0.37-0.40)$ & $<0.001$ & $0.44(0.40-0.47)$ & $<0.001$ \\
\hline Primary payer (private insurance vs other) & $0.77(0.74-0.80)$ & $<0.001$ & $0.85(0.78-0.92)$ & $<0.001$ \\
\hline \multicolumn{5}{|l|}{ Comorbidity score } \\
\hline 0 & 1.0 & & 1.0 & \\
\hline 1 & $1.61(1.49-1.74)$ & $<0.001$ & $1.63(1.47-1.81)$ & $<0.001$ \\
\hline $2-3$ & $2.57(2.39-2.76)$ & $<0.001$ & $2.47(2.24-2.73)$ & $<0.001$ \\
\hline $4-5$ & $5.74(5.22-6.30)$ & $<0.001$ & $5.31(4.68-6.02)$ & $<0.001$ \\
\hline $6-7$ & $12.17(9.90-14.96)$ & $<0.001$ & $13.41(10.33-17.41)$ & $<0.001$ \\
\hline $8-9$ & $14.96(8.65-25.86)$ & $<0.001$ & $14.11(8.07-24.66)$ & $<0.001$ \\
\hline \multicolumn{5}{|l|}{ Procedure type } \\
\hline Needle biopsy & 1.0 & & 1.0 & \\
\hline Open biopsy & $1.26(1.19-1.32)$ & $<0.001$ & $1.08(1.00-1.18)$ & 0.060 \\
\hline Craniotomy & $2.79(2.66-2.92)$ & $<0.001$ & $2.43(2.24-2.63)$ & $<0.001$ \\
\hline Weekend admission & $1.51(1.42-1.60)$ & $<0.001$ & $1.06(0.96-1.16)$ & 0.26 \\
\hline Hospital case vol, Quartile 4 vs 1 & $0.81(0.77-0.87)$ & 0.006 & $1.12(1.05-1.20)$ & 0.001 \\
\hline Surgeon case vol, Quartile 4 vs 1 & $0.79(0.75-0.83)$ & $<0.001$ & $0.85(0.78-0.93)$ & $<0.001$ \\
\hline
\end{tabular}

was no significant difference between the medium- and high-volume centers. For the subgroup of patients with more than 4 comorbidities (score $>4$ ), no consistent relationship was discernable between hospital volume and value of care. High-volume surgeon was associated with a lower value of care in the subgroup with more than 4 comorbidities, indicating poor outcomes in sick patients despite treatment by a high-volume surgeon. Further details of this analysis can be found in the Appendix Value of Care.

\section{Length of Stay}

The median LOS remained stable during the study period, from 3 days (2000) to 4 days (2009) for biopsy and at 7 days (both 2000 and 2009) for craniotomy. The median LOS was shortest at very-high-volume hospitals (top decile, $p<0.001$ ) compared with low-volume hospitals (3 vs 6 days; Fig. 6). Length of stay was also shortest for veryhigh-volume surgeons (top decile) as compared with the low-volume surgeons (Quartile 1; 3 vs 6 days, $\mathrm{p}<0.001$ ).

\section{Discussion}

We evaluated inpatient outcomes for patients who had undergone biopsy or craniotomy for primary brain tumor by using a nationally representative discharge database.
Consistent with findings for the previous decade, the results of our analysis demonstrated greater centralization of care overall for biopsies and craniotomies. ${ }^{2}$ High-volume providers achieved improved patient outcomes, including reduced in-hospital mortality and a greater number of routine discharges for high-volume hospitals and reduced mortality for high-volume surgeons. We also observed a lower complication rate for high-volume hospitals and surgeons. Moreover, surgeon volume was a stronger predictor of complication rates than hospital volume. Barker et al. studied outcomes in 38,028 adults with primary brain tumor from the NIS database, 1988-2000. ${ }^{2}$ In-hospital mortality was reported as $2.8 \%$ (2.5\% for needle biopsy and $2.9 \%$ for craniotomies), similar to the $2.6 \%$ in our population, with lower mortality and better outcomes observed with higher-volume hospitals and providers. In contrast to Barker et al., we found that postoperative complications were less frequent at higher-volume centers. Nuño et al. studied patients who had undergone craniotomy or biopsy in the NIS database and reported a reduction in mortality over the span of years studied (2001-2007), with the greatest reductions occurring at high-case-volume hospitals (45\% vs $19 \%$ reduction in low-volume hospitals). ${ }^{21}$

The present study confirms and extends the volumeoutcome relationship previously demonstrated for primary brain tumors. In addition to the reduced mortality 

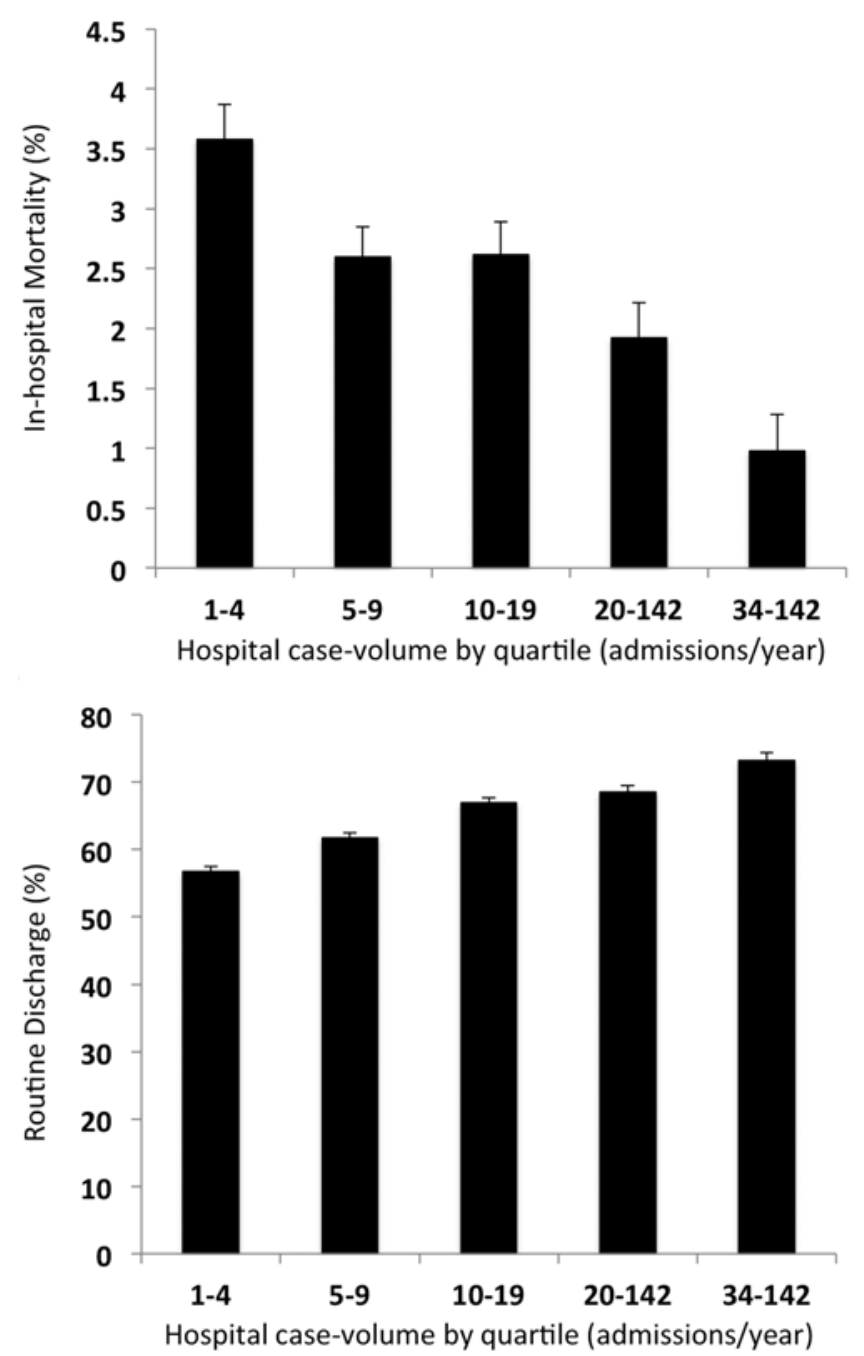

FIG. 1. Graph depicting mean in-hospital mortality (upper) and routine discharge home (lower) following biopsy or craniotomy for primary brain tumor, plotted against annual hospital caseload (grouped by quartile and highest decile).

and increased routine discharges observed at high-volume hospitals and for high-volume surgeons, postoperative complications were lower for high-volume providers. The exception was the more frequent cardiac complications at high-volume hospitals, even when adjusted for cardiac comorbidity. The more frequent occurrence of complications at low-volume centers and for low-volume surgeons may contribute to a longer LOS. Furthermore, we investigated the disparity in health care outcomes and found not only worse outcomes for African American and Hispanic patients and those not privately insured but also underutilization of high-volume surgical care by these demographic groups.

Better outcomes at high-case-volume hospitals may be associated with hospital-related factors such as a dedicated neurosurgical intensive care unit, ${ }^{10}$ specialized nursing, neuro-oncologists, and hospitalist comanagement teams. ${ }^{1}$ In our study, patients treated at high-volume hospitals and by high-volume surgeons had fewer complications. This may be tied to cumulative expertise (practice makes per-

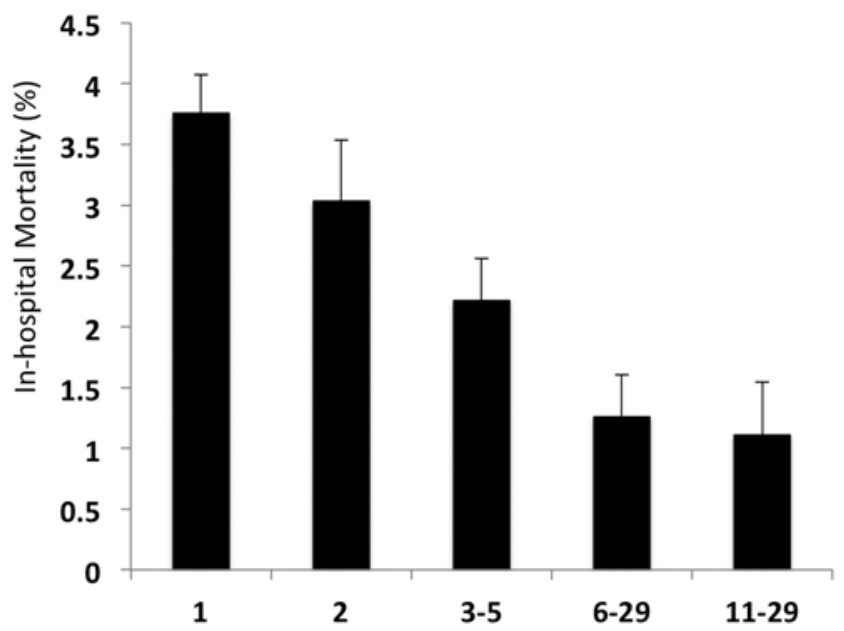

Surgeon case-volume by quartile (admissions/year)

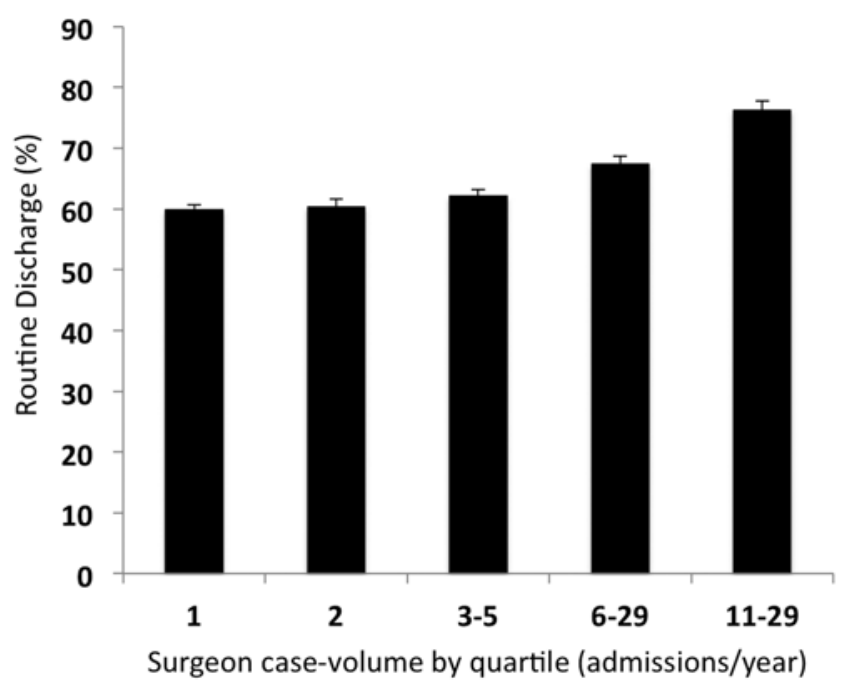

FIG. 2. Graph depicting mean in-hospital mortality (upper) and routine discharge home (lower) following biopsy or craniotomy for primary brain tumor, plotted against annual surgeon caseload (grouped by quartile and highest decile).

fect), refinement of surgical technique, as well as the use and availability of adjunctive techniques such as intraoperative electrophysiology monitoring. ${ }^{17,22,26}$ It may be that very-high-volume surgeons acquire a degree of sophistication in their clinical decision making and technical skill that contributes to more favorable outcomes. ${ }^{4}$

We detected treatment bias in our data. High-risk cases tended to concentrate more often at smaller hospitals and were more often treated by low-volume surgeons, and low-risk patients (that is, those with a younger age, fewer comorbidities, elective admissions, and private insurance) tended to be treated at high-caseload centers. These findings may be associated with differences in health status that are difficult to capture using our study method. It is unlikely, however, that patient-related risk alone can explain the volume-outcome disparity observed in our study. For one, we adjusted for these factors in our multivariate analysis. Furthermore, we isolated patients with no comorbidity and found that patients treated at high-volume centers and by high-volume surgeons have a lower mor- 


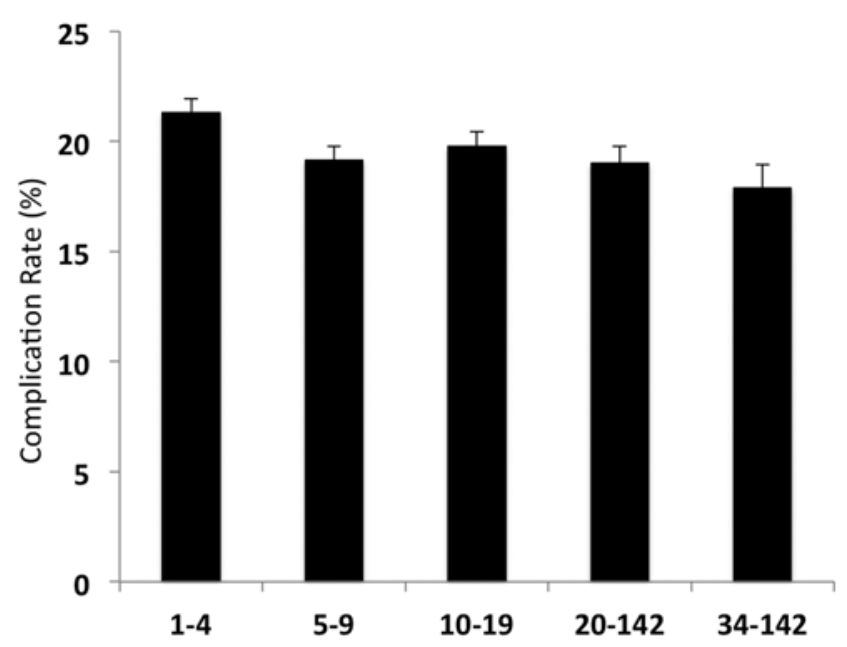

Hospital case-volume by quartile (admissions/year)

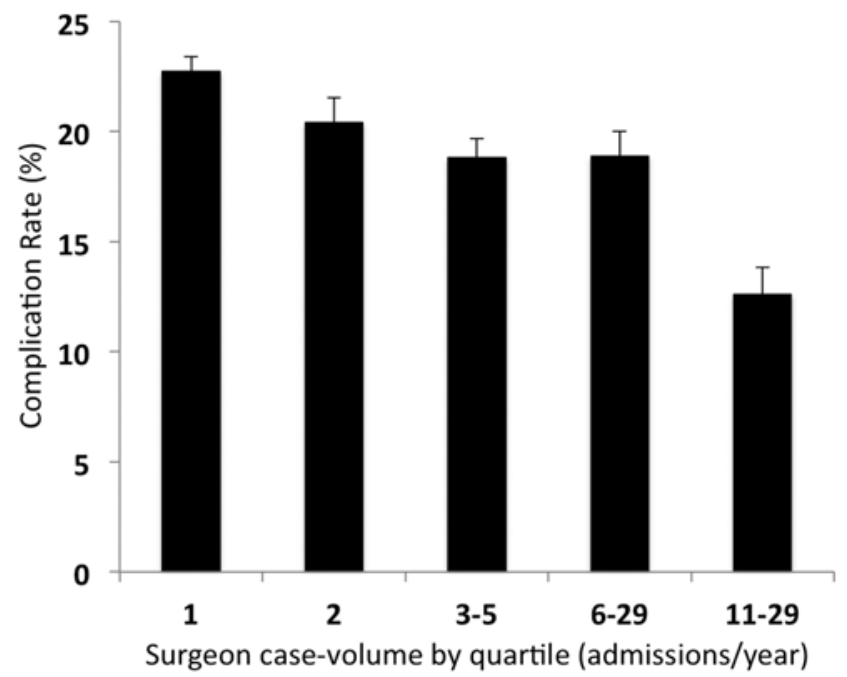

FIG. 3. Relationship between mean complications and hospital (upper) or surgeon (lower) case volume (grouped by quartile and highest decile).

tality risk and greater likelihood of a routine discharge (Appendix Table 3). This result was also observed when we repeated the analysis in patients with private insurance and in those who underwent elective surgery. The unique aspect of this analysis is that it controls for the unknown effects of comorbid disease, insurance status, and urgency of admission. ${ }^{19}$ Finally, in a separate logistic regression analysis in which patient age, race, sex, and income alone were computed, patient-related factors failed to account for the variance in outcome in terms of routine discharge, death, and complications (Nagelkerke $\mathrm{R}^{2}=0.02,0.11$, and 0.01 , respectively; with only $65.9 \%, 64.1 \%$, and $81.5 \%$, respectively, classified correctly in this model). Greater variance in outcome was explained with the inclusion of hospital and surgeon quartile (Nagelkerke $\mathrm{R}^{2}=0.30,0.30$, and 0.20 , respectively; with $98 \%, 71 \%$, and $80 \%$, respectively, classified correctly). It remains possible that there are unmeasured confounders difficult to quantify that may affect postoperative complication rates.

In response to other studies documenting volume-outcome relationships for certain complex procedures, ${ }^{16}$ third

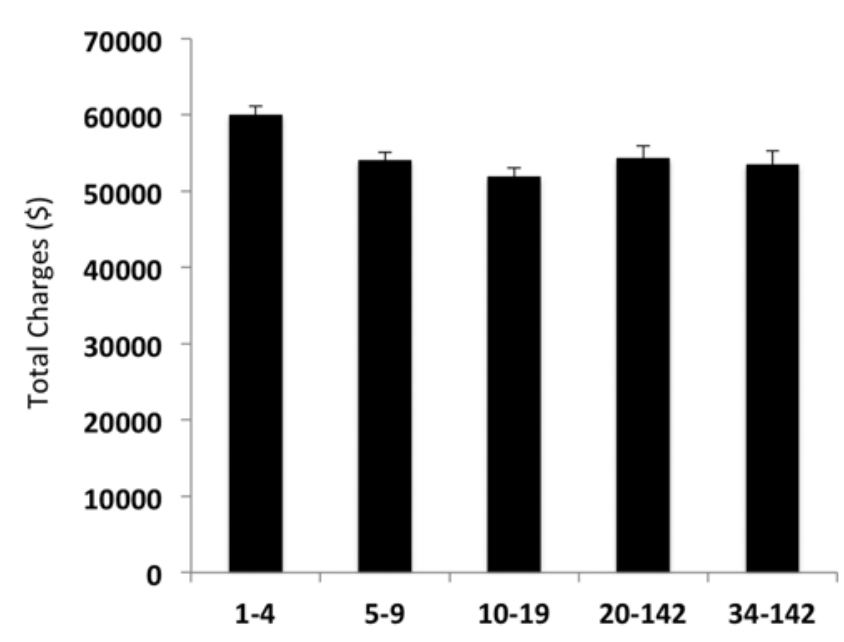

Hospital case-volume by quartile (admissions/year)

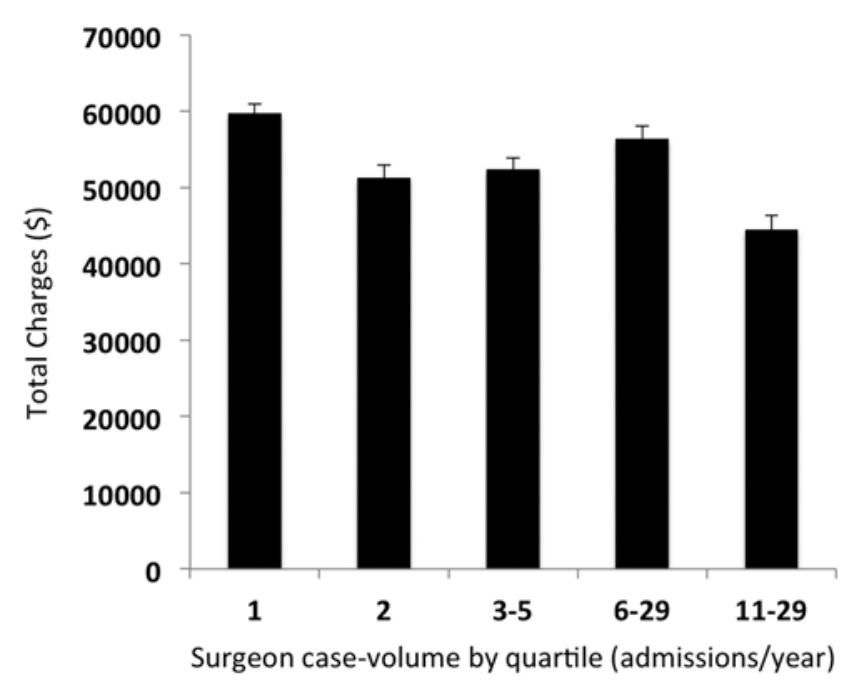

FIG. 4. Relationship between mean hospital charges and hospital (upper) or surgeon (lower) case volume (grouped by quartile and highest decile).

party payers and policymakers have developed volumebased referral initiatives. One such example is the nonprofit Leapfrog Group, a coalition of more than 100 Fortune 500 employers and public-sector purchasers, which directs patients to hospitals that perform a large volume of coronary artery bypass graft surgeries, coronary angioplasties, carotid endarterectomies, abdominal aortic aneurysm repairs, and esophagectomies. ${ }^{5}$ Several states enforce volume thresholds in certificate of need applications for new surgical centers. ${ }^{18}$

Although volume was associated with better brain tumor surgery outcomes in our study, most patients were cared for at hospitals with modest case volumes. Only a small proportion of patients were cared for at very-highvolume hospitals $(8.2 \%)$ and by very-high-volume surgeons $(8.6 \%)$. From a patient safety and outcomes perspective, we advocate further centralization of care but recognize that consolidating treatment to only high-volume providers would require increased interfacility coordination and cooperation. One solution is to promote regionalization 
TABLE 6. Complications of biopsy or craniotomy for primary brain tumor, by hospital and surgeon volume

\begin{tabular}{|c|c|c|c|c|c|c|c|c|}
\hline \multirow[b]{2}{*}{ Complication } & \multicolumn{4}{|c|}{ Hospital Vol } & \multicolumn{4}{|c|}{ Surgeon Vol } \\
\hline & $\begin{array}{l}\text { Quartile } 1 \\
(\%)\end{array}$ & $\begin{array}{c}\text { Quartile } 4 \\
(\%)\end{array}$ & OR $(95 \% \mathrm{Cl})$ & p Value* & $\begin{array}{l}\text { Quartile } 1 \\
(\%)\end{array}$ & $\begin{array}{l}\text { Quartile } 4 \\
\text { (\%) }\end{array}$ & OR $(95 \% \mathrm{Cl})$ & p Value* \\
\hline Infarction/hemorrhage & $465(1.7)$ & $271(1.0)$ & $0.99(0.86-1.16)$ & 0.980 & 407 (2.1) & $104(0.53)$ & $0.76(0.61-0.94)$ & 0.94 \\
\hline Hematoma & $245(0.9)$ & $164(0.6)$ & $0.86(0.71-1.06$ & 0.157 & $243(1.2)$ & $123(0.6)$ & $0.66(0.53-0.82)$ & 0.0001 \\
\hline Hydrocephalus & $751(2.8)$ & $641(2.4)$ & $0.87(0.60-0.75)$ & $<0.001$ & $855(4.3)$ & $245(1.2)$ & $0.85(0.74-0.98$ & 0.028 \\
\hline EVD & $718(2.7)$ & $607(2.3)$ & $0.67(0.60-0.75)$ & $<0.001$ & $824(4.2)$ & $240(1.2)$ & $0.86(0.75-1.00)$ & 0.053 \\
\hline Mechanical ventilation & $674(2.5)$ & $205(0.8)$ & $0.51(0.44-0.60)$ & $<0.001$ & $561(2.9)$ & $132(0.7)$ & $0.70(0.57-0.84)$ & 0.0002 \\
\hline DVT/PE/IVCF & $347(1.3)$ & $239(0.9$ & $0.84(0.71-0.99)$ & 0.042 & $459(2.3)$ & $124(0.6)$ & $0.80(0.65-0.98)$ & 0.030 \\
\hline Cardiac complication & $50(0.2)$ & $53(0.2)$ & $0.55(0.37-0.81)$ & 0.002 & $60(0.3)$ & $19(0.1)$ & $0.97(0.58-1.61)$ & 0.898 \\
\hline Renal complication & $280(1.1)$ & $99(0.4)$ & $0.60(0.48-0.76)$ & $<0.001$ & $304(1.5)$ & $83(0.4)$ & $0.81(0.64-1.04)$ & 0.098 \\
\hline Pulmonary complication & $1036(3.9)$ & $348(1.3)$ & $0.56(0.50-0.64)$ & $<0.001$ & $935(4.7)$ & $217(1.1)$ & $0.68(0.59-0.79)$ & $<0.001$ \\
\hline GI complication & $126(0.5)$ & $65(0.2)$ & $0.89(0.66-1.21)$ & 0.460 & $97(0.5)$ & $33(0.2)$ & $1.03(0.69-1.52)$ & 0.900 \\
\hline Infectious complication & $1020(3.8)$ & $456(1.7)$ & $0.76(0.68-0.85)$ & $<0.001$ & $940(4.8)$ & $234(1.2)$ & $0.73(0.63-0.85$ & $<0.001$ \\
\hline Implant complication & $67(0.3)$ & $64(0.2)$ & $0.62(0.43-0.86)$ & 0.005 & $97(0.5)$ & $14(0.1)$ & $0.44(0.25-0.77)$ & 0.003 \\
\hline Laceration complication & $33(0.1)$ & $34(0.1)$ & $0.57(0.35-0.93)$ & 0.021 & $29(0.2)$ & $10(0.1)$ & $1.04(0.51-2.12)$ & 0.912 \\
\hline Pneumonia & $314(1.2)$ & $160(0.6)$ & $0.87(0.72-1.01)$ & 0.159 & $277(1.4)$ & $81(0.4)$ & $0.87(0.68-1.11)$ & 0.263 \\
\hline Wound infection & $103(0.4)$ & $86(0.3)$ & $0.69(0.52-0.93)$ & 0.013 & $121(0.6)$ & $57(0.3)$ & $0.71(0.51-0.97)$ & 0.029 \\
\hline Decubitus ulcer & $139(0.5)$ & $82(0.3)$ & $0.99(0.75-1.30)$ & 0.939 & $107(0.5)$ & $55(0.3)$ & $0.65(0.47-0.90)$ & 0.008 \\
\hline
\end{tabular}

DVT = deep vein thrombosis; EVD = external ventricular drain; $\mathrm{GI}$ = gastrointestinal; IVCF = inferior vena cava filter; $\mathrm{PE}$ = pulmonary embolism.

* Boldface $p$ values indicate significance.

and centers of excellence through directed referrals in an effort to reduce the number of operations by hospitals and surgeons that very rarely perform a certain procedure. ${ }^{7} \mathrm{We}$ advocate a system in which patients are medically stabilized at low-volume centers, for instance, with steroids to reduce mass effect or antiepileptic medications for seizure control. A patient could then be safely transported for surgery performed by high-volume surgeons at a high-volume hospital. Medium-volume and high-volume surgeons also conferred a significant outcome advantage. Some researchers have suggested that focused educational programs that highlight brain tumor surgery techniques or that additional neuro-oncology fellowship training may be more viable alternatives to regionalization. ${ }^{4}$ Furthermore, high-volume centers may have greater access to electrophysiology monitoring (awake craniotomies, direct cortical stimulation), dedicated nursing staff and neuro-oncologists, as well as specialized ancillary staff dedicated to postoperative recovery. Improving access to these resources may improve care, optimize resection, and reduce morbidity. ${ }^{9}$ Our study does not establish which specific strategies or aspects of high-volume care are associated with improved outcomes. Additional study of clinical and practice barriers to selective referral, such as the distance from low- to high-volume hospitals, and the implications for patients remaining at low-volume hospitals is needed. ${ }^{11}$

Stratification of our value of care analysis by socioeconomic factors indicated that low-risk patients (those with elective admissions, high income, private insurance, and white race) are most strongly correlated with the improved outcomes of high-volume care. By comparison, African American and Hispanic patients and those without private insurance also benefit from high-volume care, and yet for this subgroup medium-volume providers demonstrated similar outcomes. We believe that a more robust referral system featuring centralization of care for patients with brain tumor should exist, but we also acknowledge that the potential advantages of obtaining care at a higher-volume center must be weighed with the potential disadvantages, such as travel distance and separation from one's support network. Although it is beyond the scope of this work to weigh the relative costs and benefits of seeking care at high-volume centers, especially for those with limited means, these personal factors may weigh heavily in care decisions given the variable life expectancy of many brain tumor patients.

Of concern are our findings that indicated the presence of racial and insurance-based disparities in the utilization of high-volume hospitals for brain tumor surgery. We have shown that an increasing percentage of patients receive surgical treatment at high-volume hospitals. While minority and Medicaid-insured patients appear to be included in this process, the rate at which these demographic groups are increasing the utilization of higher-volume centers lags behind the rate for whites or privately insured patients. It is unclear if regionalization will improve access to quality health care, particularly for minority groups, or if these initiatives might exacerbate race and insurance-based disparities. ${ }^{23}$

Several important limitations are inherent to the use of large administrative databases such as the NIS. Although the NIS database is a powerful tool to study outcomes in a relatively rare disease, future investigation into the impact of hospital and surgeon volume using more diseasespecific end points, including extent of resection, progression-free survival, and overall survival data, is needed. It should be noted that nonuniform coding practices often result in cross-coding and poor differentiation between 

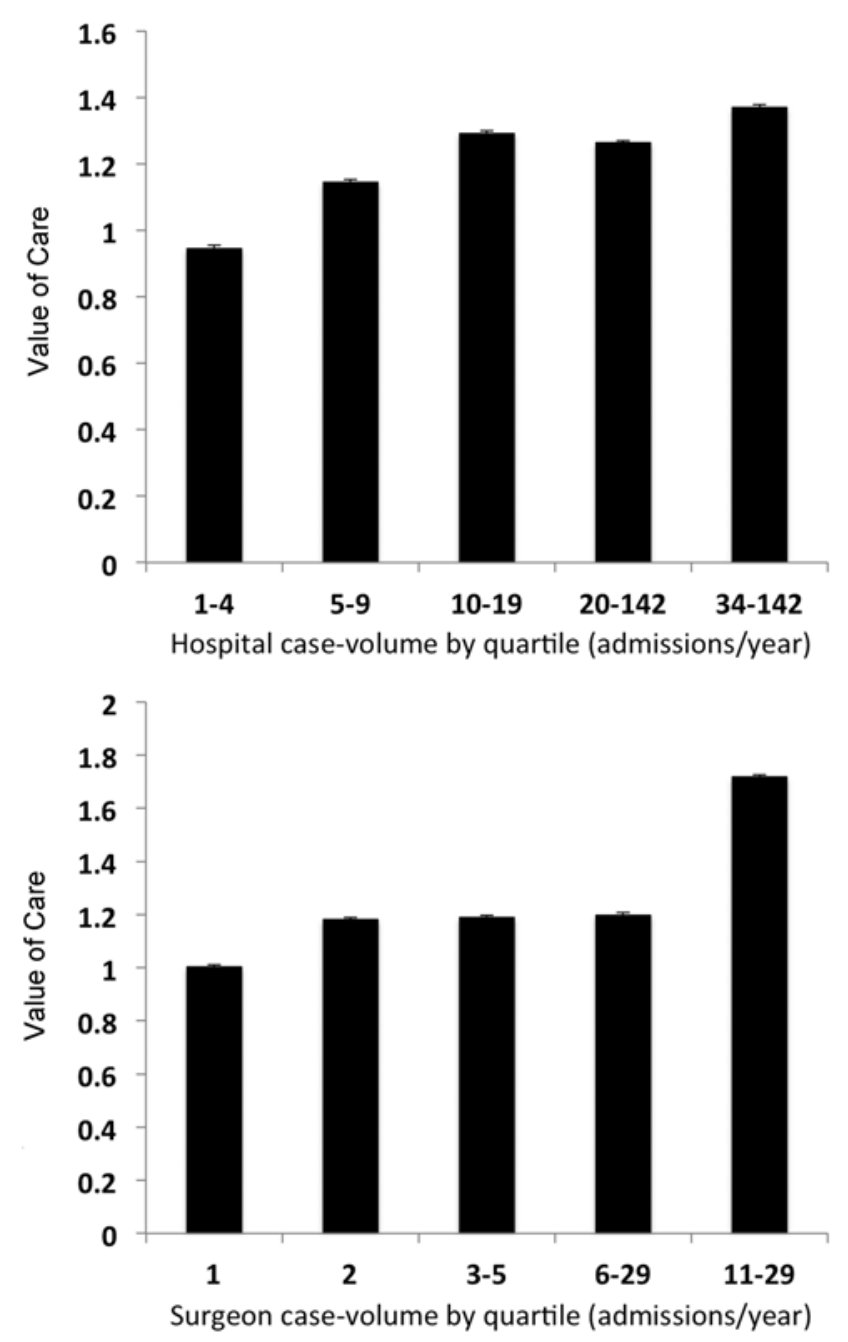

FIG. 5. Relationship between value of care and hospital (upper) or surgeon (lower) case volume (grouped by quartile and highest decile).

codes. For instance, a patient may have undergone open craniotomy for resection and may have been coded for that (01.59) as well as for open biopsy (01.14), and if the procedure were an anatomical resection, the code might also reflect lobectomy (01.53). Furthermore, some subtotal resections are coded as "open biopsy" and some as "craniotomy," which makes a discussion of the extent of resection difficult. The comorbidity score is a crude surrogate for patient health status and, with variations in coding, may not be consistent across health care providers and institutions. In addition, no information is provided on the severity of each comorbidity, how long it was present, or how well it was managed. ${ }^{17}$ The upcoming transition to ICD10-CM in the United States should improve our ability to differentiate among pathologies and to understand clinical details with more granularity. Our retrospective study was not designed to determine causality but rather the associations between surgery and outcome. Furthermore, we were not able to readily dissect referral and selection biases between institutions and surgeons. Nevertheless, this nationwide study indicates that increasing hospital and surgeon case volumes are associated with superior outcomes and

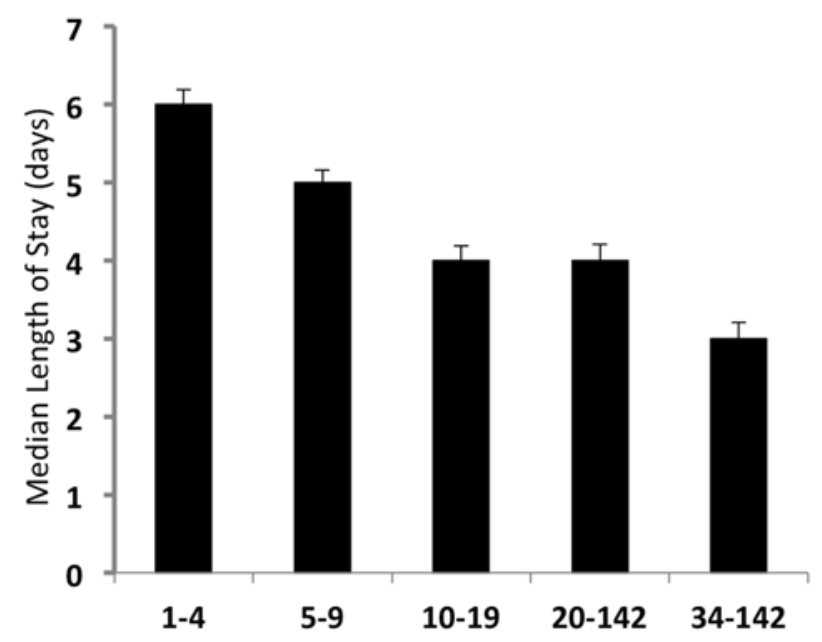

Hospital case-volume by quartile (admissions/year)

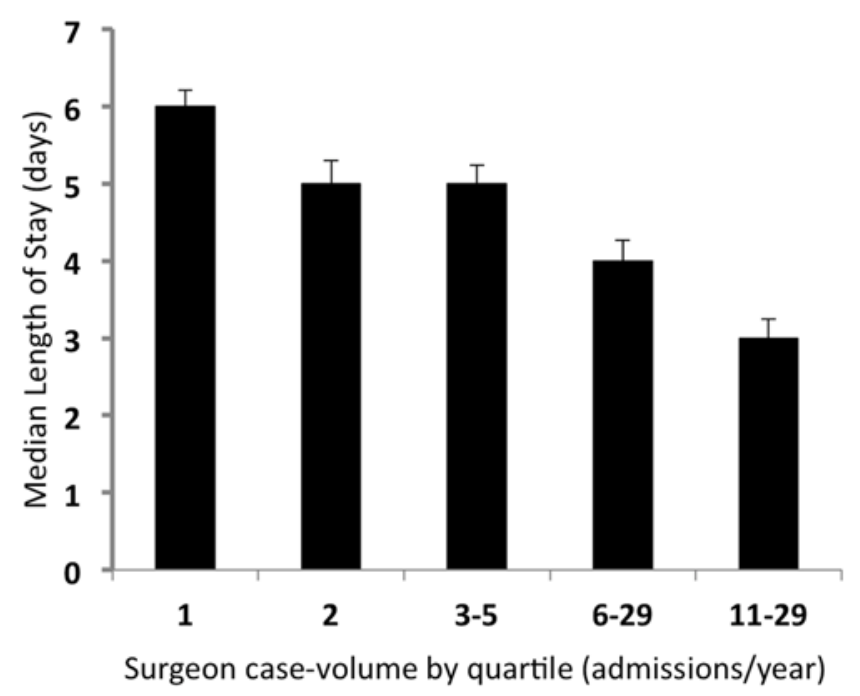

FIG. 6. Relationship between LOS and hospital (upper) or surgeon (lower) case volume (grouped by quartile and highest decile).

supports the use of regionalization for the treatment of this complex disease.

\section{Conclusions}

High-volume hospitals and surgeons tend to demonstrate superior value of care, with reduced in-hospital mortality and complications. These findings suggest that from a population perspective we might be able to improve outcomes for patients with primary supratentorial brain tumors through the regionalization of care.

\section{References}

1. Auerbach AD, Wachter RM, Cheng HQ, Maselli J, McDermott M, Vittinghoff E, et al: Comanagement of surgical patients between neurosurgeons and hospitalists. Arch Intern Med 170:2004-2010, 2010

2. Barker FG II, Curry WT Jr, Carter BS: Surgery for primary supratentorial brain tumors in the United States, 1988 to 2000: the effect of provider caseload and centralization of care. Neuro Oncol 7:49-63, 2005 
3. Barker FG II, Klibanski A, Swearingen B: Transsphenoidal surgery for pituitary tumors in the United States, 1996-2000: mortality, morbidity, and the effects of hospital and surgeon volume. J Clin Endocrinol Metab 88:4709-4719, 2003

4. Billingsley KG, Morris AM, Green P, Dominitz JA, Matthews B, Dobie SA, et al: Does surgeon case volume influence nonfatal adverse outcomes after rectal cancer resection? J Am Coll Surg 206:1167-1177, 2008

5. Birkmeyer JD, Skinner JS, Wennberg DE: Will volume-based referral strategies reduce costs or just save lives? Health Aff (Millwood) 21:234-241, 2002

6. Curry WT Jr, Carter BS, Barker FG II: Racial, ethnic, and socioeconomic disparities in patient outcomes after craniotomy for tumor in adult patients in the United States, 19882004. Neurosurgery 66:427-438, 2010

7. Dasenbrock HH, Clarke MJ, Witham TF, Sciubba DM, Gokaslan ZL, Bydon A: The impact of provider volume on the outcomes after surgery for lumbar spinal stenosis. Neurosurgery 70:1346-1354, 2012

8. Davies JM, Yanamadala V, Lawton MT: Comparative effectiveness of treatments for cerebral arteriovenous malformations: trends in nationwide outcomes from 2000 to 2009. Neurosurg Focus 33(1):E11, 2012

9. De Witt Hamer PC, Robles SG, Zwinderman AH, Duffau H, Berger MS: Impact of intraoperative stimulation brain mapping on glioma surgery outcome: a meta-analysis. J Clin Oncol 30:2559-2565, 2012

10. Diringer MN, Edwards DF: Admission to a neurologic/neurosurgical intensive care unit is associated with reduced mortality rate after intracerebral hemorrhage. Crit Care Med 29:635-640, 2001

11. Dudley RA, Johansen KL, Brand R, Rennie DJ, Milstein A: Selective referral to high-volume hospitals: estimating potentially avoidable deaths. JAMA 283:1159-1166, 2000

12. Elixhauser A, Steiner C, Harris DR, Coffey RM: Comorbidity measures for use with administrative data. Med Care 36:8-27, 1998

13. Gouma DJ, van Geenen RC, van Gulik TM, de Haan RJ, de Wit LT, Busch OR, et al: Rates of complications and death after pancreaticoduodenectomy: risk factors and the impact of hospital volume. Ann Surg 232:786-795, 2000

14. Guller U, Safford S, Pietrobon R, Heberer M, Oertli D, Jain NB: High hospital volume is associated with better outcomes for breast cancer surgery: analysis of 233,247 patients. World J Surg 29:994-1000, 2005

15. Hannan EL, Kilburn H Jr, Bernard H, O’Donnell JF, Lukacik G, Shields EP: Coronary artery bypass surgery: the relationship between inhospital mortality rate and surgical volume after controlling for clinical risk factors. Med Care 29:10941107,1991

16. Housri N, Weil RJ, Shalowitz DI, Koniaris LG: Should informed consent for cancer treatment include a discussion about hospital outcome disparities? PLoS Med 5:e214, 2008

17. Kim SS, McCutcheon IE, Suki D, Weinberg JS, Sawaya R, Lang FF, et al: Awake craniotomy for brain tumors near eloquent cortex: correlation of intraoperative cortical mapping with neurological outcomes in 309 consecutive patients. Neurosurgery 64:836-846, 2009

18. Life and death: It's your choice in surgery, or "High volume equals better results." March 21, 2000. U.S. Government Printing Office. (http://www.gpo.gov/fdsys/pkg/CREC2000-03-21/html/CREC-2000-03-21-pt1-PgE361-3.htm) [Accessed September 21, 2014]

19. Momin EN, Adams H, Shinohara RT, Frangakis C, Brem H, Quiñones-Hinojosa A: Postoperative mortality after surgery for brain tumors by patient insurance status in the United States. Arch Surg 147:1017-1024, 2012

20. Nallamothu BK, Saint S, Hofer TP, Vijan S, Eagle KA, Bernstein SJ: Impact of patient risk on the hospital volume-out- come relationship in coronary artery bypass grafting. Arch Intern Med 165:333-337, 2005

21. Nuño M, Mukherjee D, Carico C, Elramsisy A, Veeravagu A, Black KL, et al: The effect of centralization of caseload for primary brain tumor surgeries: trends from 2001-2007. Acta Neurochir (Wien) 154:1343-1350, 2012

22. Sanai N, Mirzadeh Z, Berger MS: Functional outcome after language mapping for glioma resection. $\mathbf{N}$ Engl J Med 358:18-27, 2008

23. Scarborough JE, Bennett KM, Pietrobon R, Kuo PC, Pappas TN: Trends in the utilization of high-volume hospitals by minority and underinsured surgical patients. Am Surg 76:529-538, 2010

24. Schrag D, Panageas KS, Riedel E, Cramer LD, Guillem JG, Bach PB, et al: Hospital and surgeon procedure volume as predictors of outcome following rectal cancer resection. Ann Surg 236:583-592, 2002

25. Smith ER, Butler WE, Barker FG II: Craniotomy for resection of pediatric brain tumors in the United States, 1988 to 2000: effects of provider caseloads and progressive centralization and specialization of care. Neurosurgery 54:553565,2004

26. Trinh VT, Fahim DK, Shah K, Tummala S, McCutcheon IE, Sawaya R, et al: Subcortical injury is an independent predictor of worsening neurological deficits following awake craniotomy procedures. Neurosurgery 72:160-169, 2013

\section{Author Contributions}

Conception and design: Trinh, Davies. Acquisition of data: Trinh, Davies. Analysis and interpretation of data: Trinh, Davies. Drafting the article: Trinh, Davies. Critically revising the article: all authors. Reviewed submitted version of manuscript: all authors. Statistical analysis: Trinh, Davies. Study supervision: Berger.

\section{Current Affiliation}

Dr. Trinh: Department of Neurology, Baylor College of Medicine, Houston, TX.

\section{Correspondence}

Mitchel S. Berger, Department of Neurological Surgery, University of California, San Francisco, 505 Parnassus Ave., Rm. M779, San Francisco, CA 94143-0112. email: bergerm@ neurosurg.ucsf. edu.

\section{Appendix \\ Value of Care}

As health care costs continue to rise, optimizing the value of care using population-based estimates will be paramount. Over the period studied, the total charges for care have consistently increased. Nonetheless, provider case volume shows significant impact on costs. We define value as the ratio of unit of outcome (routine discharge percentage) received per unit of cost (total hospital charges). We observe that high-case-volume providers deliver superior value of care. Assessing the value of care is challenging given the available data elements in administrative data sets such as the Nationwide Inpatient Sample (NIS). Absence of database parameters that better capture functional outcome, such as tumor progression and disease-free survival, limit the specificity of the numerator. In addition, hospital charges may not represent all costs incurred nor the actual reimbursement for services provided. To overcome these problems, more disease-specific details of clinical care can provide richer information about the relationship between quality and cost.

The unadjusted value of care was computed on a volume-quartile basis as the ratio of average routine discharge to total hospital charges. To transform the non-normally distributed total charge 
APPENDIX TABLE 1. Annual volume of primary brain tumor resections for hospitals and surgeons

\begin{tabular}{lccccc}
\hline & \multicolumn{2}{c}{ Hospital Level } & & \multicolumn{2}{c}{ Surgeon Level $^{*}$} \\
\cline { 2 - 3 } \cline { 5 - 6 } Volume Group (percentile) & Annual Caseload Category & No. of Patients & & Annual Caseload Category & No. of Patients \\
\hline Total no. & $1-4$ & 62,514 & & 36,125 \\
\hline Quartile 1 (0-25th) & $5-9$ & 16,941 & & 1 & 14,765 \\
\hline Quartile 2 (26th-50th) & $10-19$ & 16,462 & & $3-5$ & 8195 \\
\hline Quartile 3 (51st-75th) & $20-142$ & 14,131 & & $6-29$ & 8048 \\
\hline Quartile 4 (76th-100th) & $34-142$ & 5109 & $11-29$ & 3113 \\
\hline Top decile (90th-100th) & & & & \\
\hline
\end{tabular}

* Incomplete reporting in the data set.

APPENDIX TABLE 2. Discharge disposition for patients undergoing surgical treatment for primary brain tumor

\begin{tabular}{|c|c|c|c|c|c|}
\hline \multirow[b]{2}{*}{ Procedure } & \multicolumn{5}{|c|}{ Discharge Disposition (\%) } \\
\hline & Home & Transfer to Short-Term Facility & Transfer to Other Facility & Home Health & Deceased \\
\hline Needle biopsy only $(n=35,116)$ & $24,108(68.7)$ & $529(1.5)$ & $6044(17.2)$ & $3697(10.5)$ & $669(1.9)$ \\
\hline Craniotomy only $(n=25,350)$ & $14,504(57.2)$ & $475(1.9)$ & $6611(26.1)$ & $2758(10.9)$ & $894(3.5)$ \\
\hline Both needle biopsy \& craniotomy $(n=2048)$ & $1133(55.3)$ & $15(0.7)$ & $593(29.0)$ & $227(11.1)$ & $79(3.9)$ \\
\hline
\end{tabular}

APPENDIX TABLE 3. Effect of hospital high-volume caseload on outcome in patient subgroups*

\begin{tabular}{lcc}
\hline \multirow{2}{*}{ Subgroup } & \multicolumn{2}{c}{ OR $(95 \%$ Cl) $\dagger$} \\
\cline { 2 - 3 } Race & Mortality & Routine Discharge \\
\hline White & $0.18(0.08-0.44)$ & $4.00(3.33-4.81)$ \\
\hline AA & - & $1.5(1.16-1.95)$ \\
\hline Hispanic & $7.5(2.75-26.69)$ & $1.85(1.12-3.08)$ \\
\hline Primary payer & \multicolumn{3}{c}{} \\
\hline Private insurance & $0.41(0.30-0.56)$ & $4.5(3.6-5.5)$ \\
\hline Medicaid & $1.64(0.66-4.11)$ & $8.00(3.13-20.5)$ \\
\hline Admission type & & \\
\hline Elective & $0.03(0.10-0.55)$ & $4.2(3.48-5.07)$ \\
\hline Emergency or urgent & $0.35(0.14-0.84)$ & $1.71(1.37-2.12)$ \\
\hline Medical comorbidities & & \\
\hline 0 & $0.48(0.25-0.94)$ & $15.15(6.08-37.76)$ \\
\hline 1 & $0.65(0.41-1.02)$ & $8.54(4.48-16.31)$ \\
\hline$\geq 2$ & $0.33(0.14-0.80)$ & $4.93(3.84-6.33)$ \\
\hline Procedure type & & \\
\hline Needle biopsy & $0.32(0.13-0.78)$ & $5.56(4.19-7.38)$ \\
\hline Craniotomy & $0.22(0.09-0.54)$ & $4.08(3.26-5.09)$ \\
\hline AA $=$ Afican American & &
\end{tabular}

$\mathrm{AA}=$ African American.

* Exploratory subgroup analysis showed no significant difference in the volume-outcome relationship for several prognostic factors, with the exception of a weaker relationship between volume and mortality in AAs and patients with Medicaid. High-caseload hospitals and surgeons demonstrated an outcome advantage across admission type and medical comorbidity category. The difference in outcomes between patients treated at high- and low-volume hospitals was present at all patient ages. An odds ratio could not be computed between volume and mortality for AAs because of so few counts present at high-volume centers; $82.3 \%$ of AAs were treated at hospitals with an annual case volume of 25 or more cases, and the mortality rate in this subgroup was $5.4 \%$. Only $2.6 \%$ of AAs were treated at centers with an annual case volume of 50 or more cases, and the mortality rate in this subgroup was $0 \%$. $\dagger$ Odds ratio per increase in caseload quartile. data, a logarithmic transformation was applied. One-way ANOVA was then conducted to determine if value of care was different for each hospital quartile.

We further adjusted for emergency department (ED) admission rates as a major confounder to compute the adjusted value of care. Assuming an average routine discharge rate for ED admissions extrapolated from the available data, a discharge rate for non-ED admissions for each hospital was computed in the following manner: (ED discharge rate $\times$ number of ED discharges) + (non-ED discharge rates $\times$ number of non-ED discharges) $=$ routine discharge percentage $\times$ total discharges. This discharge rate for non-ED admissions was used to compute a risk-adjusted value, defined as (risk-adjusted outcome $\times$ discharge rate for non-ED admissions)/ cost.

This calculation was repeated for private insurance, median income, race, and medical comorbidity. Appendix Fig. 1 shows statistically significantly positive correlations between higher volume status and value of care for both surgeons and hospitals for all factors analyzed. The one exception was for patients with high comorbidity indices, in which case higher volume providers and facilities demonstrated lower value ratios. A 1-way ANOVA was conducted to determine if value of care was different across hospital quartiles, repeating the computation to adjust for each potential confounder. Hospital charge was analyzed as a logarithmic transformation to correct for positive skew. Value of care was normally distributed for each group. Heterogeneity of variances was present; therefore, Welch ANOVA and the Games-Howell post hoc test were used. Value of care was statistically significantly different between hospital quartiles (Appendix Tables 6 and 7). Games-Howell post hoc analysis revealed the increase in value of care with hospital and surgeon quartile was statistically significant at nearly every interval.

Limitations of our value of care model include the use of routine discharge as a surrogate for functional outcome, which does not completely capture the functional status on discharge even though we attempted to adjust for severity of presenting illness and to account for medical comorbidities. In addition, our denominator of hospital charges accounts for the amount that hospitals bill for services but does not reflect how much hospital services actually cost or the specific amounts that hospitals receive in payment.

\section{Evaluation of Model}

Once the coefficients for the model have been obtained, it is necessary to check the accuracy of the model. This can be done through several statistical tests. The omnibus test for model coef- 

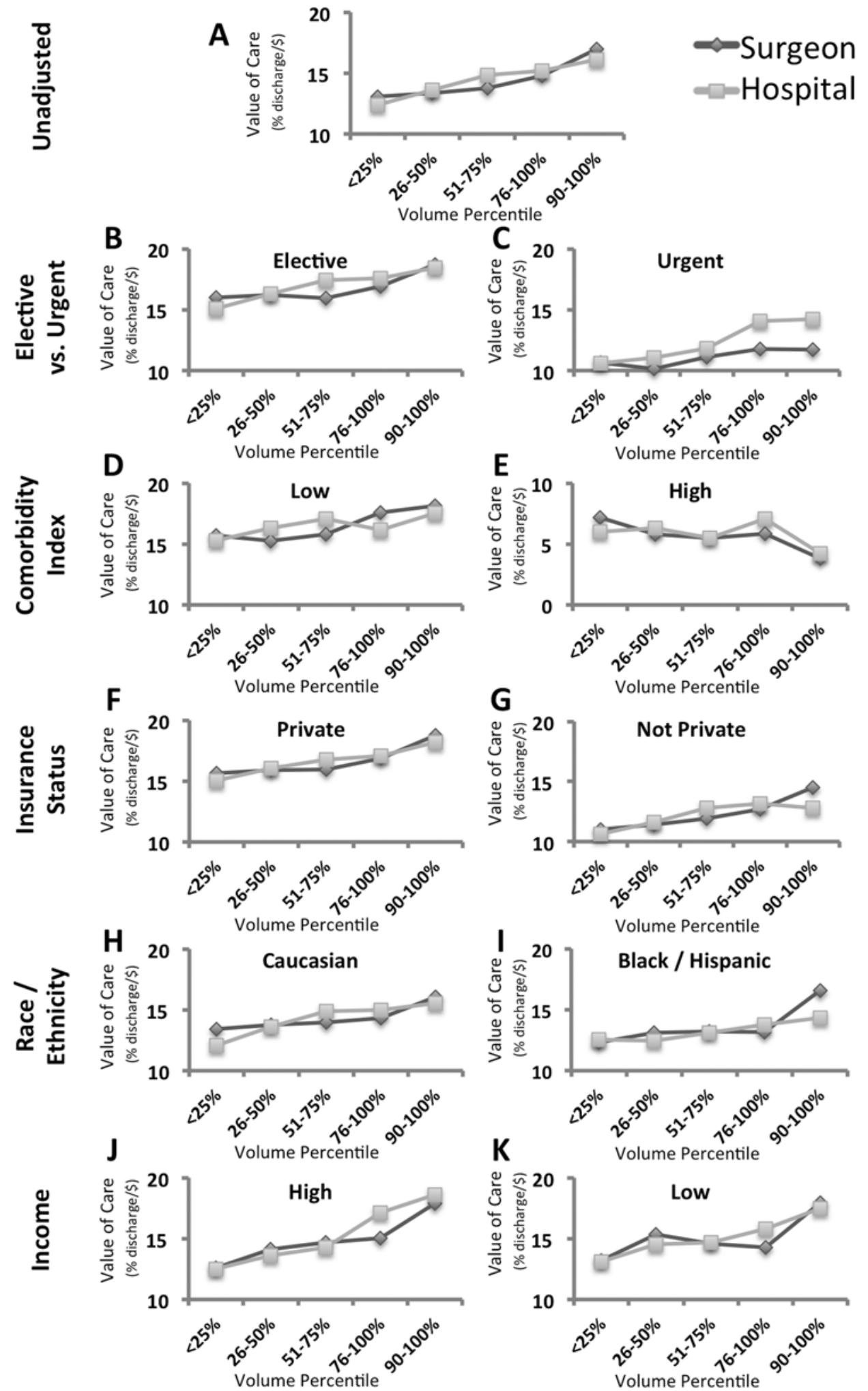

APPENDIX FIG. 1. Relationship between mean value of care (\% routine discharge/log hospital charges) and volume quartile for both hospitals and surgeons. Volume of care was computed on raw unadjusted data $(\mathbf{A})$ and subsequently adjusted for low-risk characteristics, including elective admission $(B)$, low $(0$ or 1$)$ comorbidity score $(D)$, private insurance $(F)$, white race $(H)$, and highest income quartile $(\mathrm{J})$. Value ratios were likewise computed and adjusted for high-risk characteristics, including urgent or emergent admission (C), high ( $\geq 4$ ) comorbidity score (E), non-private insurance (G), African American or Hispanic race (I), and low (1st or 2nd) income quartile (K). Data are plotted with the standard error. 
APPENDIX TABLE 4. Relationships between surgeon case volume and mortality, routine discharge, and complications*

\begin{tabular}{|c|c|c|c|}
\hline Surgeon Case Vol & In-Hospital Mortality & Routine Discharge & Complications \\
\hline \multicolumn{4}{|l|}{ Quartile $1(n=14,765)$} \\
\hline Rate & $3.8 \%$ & $59.9 \%$ & $22.7 \%$ \\
\hline Adjusted OR (95\% Cl) & 1.0 (Reference) & 1.0 (Reference) & 1.0 (Reference) \\
\hline \multicolumn{4}{|l|}{ Quartile $2(n=5195)$} \\
\hline Rate & $3.0 \%$ & $60.4 \%$ & $20.4 \%$ \\
\hline Adjusted OR (95\% Cl) & $1.2(0.95-1.56)$ & $0.94(0.86-1.03)$ & $1.01(0.90-1.13)$ \\
\hline$p$ value & 0.12 & 0.20 & 0.87 \\
\hline \multicolumn{4}{|l|}{ Quartile $3(n=8116)$} \\
\hline Rate & $2.2 \%$ & $62.4 \%$ & $18.8 \%$ \\
\hline Adjusted OR $(95 \% \mathrm{Cl})$ & $0.60(0.46-0.78)$ & $0.94(0.86-1.03)$ & $0.79(0.71-0.87)$ \\
\hline$p$ value & $<0.001$ & 0.19 & $<0.001$ \\
\hline \multicolumn{4}{|l|}{ Quartile $4(n=8048)$} \\
\hline Rate & $1.3 \%$ & $67.4 \%$ & $18.9 \%$ \\
\hline Adjusted OR $(95 \% \mathrm{Cl})$ & $0.24(0.15-0.36)$ & $1.13(1.03-1.25)$ & $0.86(0.77-0.96)$ \\
\hline$p$ value & $<0.001$ & 0.013 & 0.008 \\
\hline \multicolumn{4}{|l|}{ Top decile $(n=3113)$} \\
\hline Rate & $1.1 \%$ & $76.3 \%$ & $12.6 \%$ \\
\hline Adjusted OR (95\% Cl) & $0.63(0.41-0.96)$ & $1.50(1.29-1.70)$ & $0.57(0.48-0.67)$ \\
\hline$p$ value & 0.034 & $<0.001$ & $<0.001$ \\
\hline
\end{tabular}

* All analyses are adjusted for patient age, sex, race, comorbid disease, type of procedure, and weekend admission.

ficients chi-square test is $<0.001$, indicating that our model with predictors is significantly better than the model without predictors. ${ }^{\mathrm{a}}$ The Nagelkerke pseudo $\mathrm{R}^{2}$ is a measure of the strength of the association between the dependent variable and the predictor variables. ${ }^{b}$ Pseudo $\mathrm{R}^{2}$ is an approximation analogous to the linear regression model $\mathrm{R}^{2}$, and though there is no standard cutoff used for pseudo $\mathrm{R}^{2}$ values, a Nagelkerke pseudo $\mathrm{R}^{2}$ value ranging between 0.2 and 0.4 is considered a sufficient level of explained variance. ${ }^{c}$ For logistic regression models including hospital volume as a predictor, the Nagelkerke pseudo $\mathrm{R}^{2}$ values for our data are as follows: mortal-

\section{APPENDIX TABLE 5. Relationships between hospital case volume and mortality, routine discharge, and} complications*

\begin{tabular}{|c|c|c|c|}
\hline Hospital Case Vol & In-Hospital Mortality & Routine Discharge & Complications \\
\hline \multicolumn{4}{|l|}{ Quartile 1 ( $n=16,941)$} \\
\hline Rate & $3.6 \%$ & $56.8 \%$ & $21.3 \%$ \\
\hline Adjusted OR $(95 \% \mathrm{Cl})$ & 1.0 (Reference) & 1.0 (Reference) & 1.0 (Reference) \\
\hline \multicolumn{4}{|l|}{ Quartile $2(n=16,462)$} \\
\hline Rate & $2.6 \%$ & $61.9 \%$ & $19.2 \%$ \\
\hline Adjusted OR (95\% Cl) & $0.69(0.56-0.65)$ & $1.21(1.12-1.30)$ & $1.01(0.93-1.09)$ \\
\hline$p$ value & $<0.001$ & $<0.001$ & 0.87 \\
\hline \multicolumn{4}{|l|}{ Quartile $3(n=14,131)$} \\
\hline Rate & $2.6 \%$ & $67 \%$ & $19.8 \%$ \\
\hline Adjusted OR (95\% Cl) & $1.03(0.85-1.26)$ & $1.31(1.21-1.41)$ & $1.11(1.02-1.21)$ \\
\hline$p$ value & 0.72 & $<0.001$ & 0.02 \\
\hline \multicolumn{4}{|l|}{ Quartile $4(n=14,980)$} \\
\hline Rate & $1.9 \%$ & $68.6 \%$ & $19 \%$ \\
\hline Adjusted OR $(95 \% \mathrm{Cl})$ & $0.72(0.57-0.92)$ & $1.14(1.05-1.23)$ & $1.08(0.98-1.19)$ \\
\hline$p$ value & 0.008 & 0.001 & 0.09 \\
\hline \multicolumn{4}{|l|}{ Top decile $(n=5109)$} \\
\hline Rate & $1.0 \%$ & $73.2 \%$ & $17.9 \%$ \\
\hline Adjusted OR (95\% Cl) & $0.52(0.36-0.75)$ & $1.17(1.06-1.31)$ & $1.18(1.05-1.32)$ \\
\hline$p$ value & $<0.001$ & 0.003 & 0.006 \\
\hline
\end{tabular}

* All analyses are adjusted for patient age, sex, race, comorbid disease, type of procedure, and weekend admission. 
APPENDIX TABLE 6. Games-Howell post hoc analysis: multiple comparisons for value of care with top hospital decile*

\begin{tabular}{|c|c|c|c|c|}
\hline Hospital Quartile & Value Comparison & $\mathrm{p}$ Value $\dagger$ & Value Comparison & $p$ Value $†$ \\
\hline \multicolumn{5}{|l|}{ Unadjusted } \\
\hline 1 & $-3.74 \pm 0.05$ & $<0.001$ & & \\
\hline 2 & $-2.47 \pm 0.05$ & $<0.001$ & & \\
\hline 3 & $-1.28 \pm 0.05$ & $<0.001$ & & \\
\hline 4 & $-0.93 \pm 0.05$ & $<0.001$ & & \\
\hline Admission status & \multicolumn{2}{|c|}{ Elective } & \multicolumn{2}{|c|}{ Urgent/emergent } \\
\hline 1 & $-3.36 \pm 0.03$ & $<0.001$ & $-3.61 \pm 0.09$ & $<0.001$ \\
\hline 2 & $-2.15 \pm 0.03$ & $<0.001$ & $-3.13 \pm 0.09$ & $<0.001$ \\
\hline 3 & $-1.02 \pm 0.03$ & $<0.001$ & $-2.35 \pm 0.09$ & $<0.001$ \\
\hline 4 & $-0.91 \pm 0.03$ & $<0.001$ & $-0.14 \pm 0.10$ & 0.56 \\
\hline Comorbidity score & \multicolumn{2}{|c|}{$0-1$} & \multicolumn{2}{|c|}{$\geq 4$} \\
\hline 1 & $-2.25 \pm 0.03$ & $<0.001$ & $-1.75 \pm 0.02$ & $<0.001$ \\
\hline 2 & $-1.21 \pm 0.03$ & $<0.001$ & $-2.08 \pm 0.02$ & $<0.001$ \\
\hline 3 & $-0.45 \pm 0.03$ & $<0.001$ & $-1.25 \pm 0.03$ & $<0.001$ \\
\hline 4 & $-1.39 \pm 0.02$ & $<0.001$ & $-2.84 \pm 0.04$ & $<0.001$ \\
\hline Insurance status & \multicolumn{2}{|c|}{ Private } & \multicolumn{2}{|c|}{ Not private } \\
\hline 1 & $-3.17 \pm 0.03$ & $<0.001$ & $-2.19 \pm 0.02$ & $<0.001$ \\
\hline 2 & $-2.15 \pm 0.03$ & $<0.001$ & $-1.19 \pm 0.02$ & $<0.001$ \\
\hline 3 & $-1.46 \pm 0.03$ & $<0.001$ & $-0.04 \pm 0.03$ & 0.44 \\
\hline 4 & $-1.15 \pm 0.03$ & $<0.001$ & $0.36 \pm 0.03$ & $<0.001$ \\
\hline Race/ethnicity & \multicolumn{2}{|c|}{ White } & \multicolumn{2}{|c|}{ AA/Hispanic } \\
\hline 1 & $-3.45 \pm 0.02$ & $<0.001$ & $-1.62 \pm 0.06$ & $<0.001$ \\
\hline 2 & $-1.90 \pm 0.03$ & $<0.001$ & $-1.76 \pm 0.06$ & $<0.001$ \\
\hline 3 & $-0.65 \pm 0.03$ & $<0.001$ & $-0.97 \pm 0.07$ & $<0.001$ \\
\hline 4 & $-0.52 \pm 0.03$ & $<0.001$ & $-0.23 \pm 0.07$ & 0.012 \\
\hline Income quartile & \multicolumn{2}{|c|}{ 4th } & \multicolumn{2}{|c|}{ 1st or 2nd } \\
\hline 1 & $-6.08 \pm 0.04$ & $<0.001$ & $-4.04 \pm 0.09$ & $<0.001$ \\
\hline 2 & $-4.98 \pm 0.04$ & $<0.001$ & $-2.69 \pm 0.09$ & $<0.001$ \\
\hline 3 & $-4.33 \pm 0.04$ & $<0.001$ & $-2.45 \pm 0.10$ & $<0.001$ \\
\hline 4 & $-1.49 \pm 0.05$ & $<0.001$ & $-1.12 \pm 0.10$ & $<0.001$ \\
\hline
\end{tabular}

\footnotetext{
* Comparisons were made with data that were either unadjusted or adjusted for various surrogates for risk: low risk-elective cases, high income, private insurance, white race, low comorbidity score; and high risk-urgent or emergent cases, low income, no private insurance, Hispanic or African American race, higher comorbidity score. Values are expressed as the difference in the mean value of care \pm standard error, compared with the top hospital decile.

† Boldface $p$ values indicate statistical significance.
}

ity $\left(\mathrm{R}^{2}=0.30\right)$, routine discharge $\left(\mathrm{R}^{2}=0.30\right)$, complications $\left(\mathrm{R}^{2}\right.$ $=0.20)$. For models with surgeon as a predictor, the Nagelkerke pseudo $\mathrm{R}^{2}$ values are as follows: mortality $\left(\mathrm{R}^{2}=0.11\right)$, routine discharge $\left(R^{2}=0.30\right)$, and complications $\left(R^{2}=0.20\right)$. These approximations (pseudo $\mathrm{R}^{2}$ ) are useful when comparing competing models for the same data.

We chose to include variables in our final model if their inclusion led to a significant overall improvement in the explanatory power of the model (increased pseudo $\mathrm{R}^{2}$ statistic). We also examined the classification table, which compares the observed values to the predicted values in our model. For the logistic regression model including hospital volume as a predictor, we report the overall percentage of those correctly classified as follows: mortality (98\%), routine discharge (71\%), and complication (80\%). For the logistic regression model including surgeon volume as a predictor, we report the overall percentage of those correctly classified as follows: mortality (98\%), routine discharge $(72 \%)$, and complication (80\%). It appears that our model is acceptable; however, there are certainly confounders and other variables not accounted for that would improve our model fit. The strongest models are hospital as a predictor of mortality $\left(\mathrm{R}^{2}=0.30\right)$ and routine discharge $\left(\mathrm{R}^{2}=\right.$ $0.30)$ and surgeon as a predictor of routine discharge $\left(\mathrm{R}^{2}=0.30\right)$. Surgeon as a predictor of mortality is the weakest model $\left(\mathrm{R}^{2}=\right.$ $0.11)$.

\section{References}

a. Bonhomme V, Llabres V, Dewandre PY, Brichant JF, Hans P: Combined use of Bispectral Index and A-Line Autoregressive Index to assess anti-nociceptive component of balanced anaesthesia during lumbar arthrodesis. Br J Anaesth 96:353-360, 2006

b. Bonhomme V, Uutela K, Hans G, Maquoi I, Born JD, Brichant JF, et al: Comparison of the surgical Pleth IndexTM with haemodynamic variables to assess nociception-anti-nociception balance during general anaesthesia. Br J Anaesth 106:101-111, 2011

c. Nagelkerke NJD: A note on a general definition of the coefficient of determination. Biometrika 78:691-692, 1991 
APPENDIX TABLE 7. Games-Howell post-hoc analysis: multiple comparisons for value of care with top surgeon decile*

\begin{tabular}{|c|c|c|c|c|}
\hline Surgeon Quartile & Value Comparison & $\mathrm{p}$ Value $\dagger$ & Value Comparison & p Value \\
\hline \multicolumn{5}{|l|}{ Unadjusted } \\
\hline 1 & $-3.90 \pm 0.02$ & $<0.001$ & & \\
\hline 2 & $-3.61 \pm 0.03$ & $<0.001$ & & \\
\hline 3 & $-3.19 \pm 0.02$ & $<0.001$ & & \\
\hline 4 & $-2.21 \pm 0.03$ & $<0.001$ & & \\
\hline Admission status & \multicolumn{2}{|c|}{ Elective } & \multicolumn{2}{|c|}{ Urgent/emergent } \\
\hline 1 & $-2.72 \pm 0.07$ & $<0.001$ & $-1.08 \pm 0.03$ & $<0.001$ \\
\hline 2 & $-2.52 \pm 0.09$ & $<0.001$ & $-1.57 \pm 0.03$ & $<0.001$ \\
\hline 3 & $-2.80 \pm 0.08$ & $<0.001$ & $-0.60 \pm 0.03$ & $<0.001$ \\
\hline 4 & $-1.79 \pm 0.08$ & $<0.001$ & $0.06 \pm 0.03$ & 0.37 \\
\hline Comorbidity score & \multicolumn{2}{|c|}{$0-1$} & \multicolumn{2}{|c|}{$\geq 4$} \\
\hline 1 & $-2.44 \pm 0.04$ & $<0.001$ & $3.37 \pm 0.05$ & $<0.001$ \\
\hline 2 & $-2.88 \pm 0.04$ & $<0.001$ & $1.20 \pm 0.05$ & $<0.001$ \\
\hline 3 & $-2.33 \pm 0.04$ & $<0.001$ & $1.68 \pm 0.05$ & $<0.001$ \\
\hline 4 & $-0.54 \pm 0.04$ & $<0.001$ & $2.05 \pm 0.05$ & $<0.001$ \\
\hline Insurance status & \multicolumn{2}{|c|}{ Private } & \multicolumn{2}{|c|}{ Not private } \\
\hline 1 & $-3.13 \pm 0.03$ & $<0.001$ & $-3.49 \pm 0.03$ & $<0.001$ \\
\hline 2 & $-2.90 \pm 0.04$ & $<0.001$ & $-3.11 \pm 0.03$ & $<0.001$ \\
\hline 3 & $-2.83 \pm 0.03$ & $<0.001$ & $-2.58 \pm 0.03$ & $<0.001$ \\
\hline 4 & $-1.88 \pm 0.04$ & $<0.001$ & $-1.79 \pm 0.03$ & $<0.001$ \\
\hline Race/ethnicity & \multicolumn{2}{|c|}{ White } & \multicolumn{2}{|c|}{ AA/Hispanic } \\
\hline 1 & $-2.66 \pm 0.03$ & $<0.001$ & $-1.39 \pm 0.07$ & $<0.001$ \\
\hline 2 & $-2.32 \pm 0.04$ & $<0.001$ & $-0.98 \pm 0.08$ & $<0.001$ \\
\hline 3 & $-2.11 \pm 0.04$ & $<0.001$ & $-1.23 \pm 0.08$ & $<0.001$ \\
\hline 4 & $-1.75 \pm 0.04$ & $<0.001$ & $-0.87 \pm 0.08$ & $<0.001$ \\
\hline Income quartile & \multicolumn{2}{|c|}{ 4th } & \multicolumn{2}{|c|}{ 1st or 2nd } \\
\hline 1 & $-5.34 \pm 0.06$ & $<0.001$ & $-5.26 \pm 0.10$ & $<0.001$ \\
\hline 2 & $-3.79 \pm 0.06$ & $<0.001$ & $-3.06 \pm 0.11$ & $<0.001$ \\
\hline 3 & $-3.25 \pm 0.06$ & $<0.001$ & $-3.84 \pm 0.10$ & $<0.001$ \\
\hline 4 & $-2.87 \pm 0.06$ & $<0.001$ & $-4.07 \pm 0.14$ & $<0.001$ \\
\hline
\end{tabular}

* Comparisons were made with data that were either unadjusted or adjusted for various surrogates for risk: low risk-elective cases, high income, private insurance, white race, low comorbidity score; high risk-urgent or emergent cases, low income, no private insurance, Hispanic or AA race, higher comorbidity score. Values are shown as the difference in the mean value of care \pm standard error, compared with the top surgeon decile.

† Boldface $p$ values indicate statistical significance. 